\title{
Marine amphipods (Paryhale hawaiensis) as an alternative feed for the lined seahorse (Hippocampus erectus, Perri 1810): nutritional value and feeding trial
}

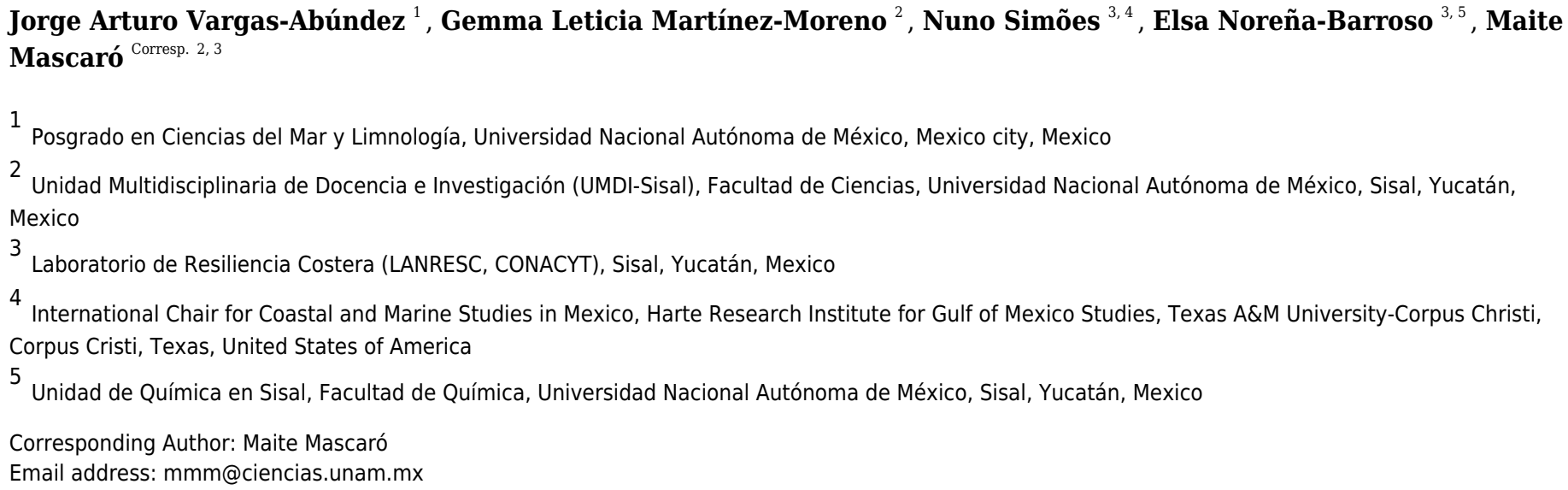

Finding new alternatives to traditional live preys such as Artemia and rotifers, which do not always promote optimal fish growth and survival, is required for the successful aquaculture of highly specialized predatory species, including seahorses. The present study assessed the nutritional value of an interesting marine amphipod (Paryhale hawaiensis), and evaluates through a feeding trial its potential use as a natural prey for 10-months lined seahorse, Hippocampus erectus. P. hawaiensis showed high levels of valuable lipids (20.4-26.7\% on dry matter basis) and polyunsaturated fatty acids (PUFAs) ( $26.4-41 \%$ of total FAs), including the long-chain PUFAs (LC-PUFAs) arachidonic acid (ARA) (2.9-7.7\%), eicosapentaenoic acid (EPA) (4.3-6.5\%) and docosahexaenoic acid (DHA) (2.1-6.2\%). A comparison between wild-captured and cultured amphipods revealed a significant improvement of the amphipod FA profile in terms of DHA\%, total omega-3 (n3) FAs and $\mathrm{n} 3 / \mathrm{n} 6$ ratio when employing both a conventional amphipod culture based on a commercial shrimp diet, and, to a lesser extent, a large (3500 L) biofloc system. Seahorses fed with frozen/wild amphipods, either singly or in combination with Artemia enriched with Super Selco ${ }^{\circledR}$ (INVE Aquaculture, Belgium) for 57 days, substantially improved seahorse growth and FA profiles in terms of ARA, EPA and DHA\%, including indiex associated to marine sources, such as $\Sigma \mathrm{n} 3$ and n3/n6, compared to a diet based solely on enriched Artemia. These results support the use of marine amphipods as an alternative food organism for juvenile $H$. erectus and suggest a potential use for general marine aquaculture. 
1 Marine amphipods (Paryhale hawaiensis) as an

2 alternative feed for the lined seahorse (Hippocampus

3 erectus, Perry 1810): nutritional value and feeding trial

4

5

6

7

8

9

10

Jorge Arturo Vargas-Abúndez ${ }^{1}$, Gemma Martinez-Moreno ${ }^{2}$, Nuno Simões ${ }^{3,4}$, Elsa NoreñaBarroso $^{3,5}$, Maite Mascaró 2,3

${ }^{1}$ Posgrado en Ciencias del Mar y Limnología, Universidad Nacional Autónoma de México, Circuito Exterior, Ciudad Universitaria, 04510 Mexico City, Mexico

${ }^{2}$ Unidad Multidisciplinaria de Docencia e Investigación (UMDI-Sisal), Facultad de Ciencias, Universidad Nacional Autónoma de México, Sisal, Yucatán, Mexico

${ }^{3}$ Laboratorio de Resiliencia Costera (LANRESC, CONACYT), Sisal, Yucatán, Mexico

${ }^{4}$ International Chair for Coastal and Marine Studies in Mexico, Harte Research Institute for Gulf of Mexico Studies, Texas A\&M University-Corpus Christi, United States of America

${ }^{5}$ Unidad de Química en Sisal, Facultad de Química, Universidad Nacional Autónoma de México, Sisal, Yucatán, Mexico

Corresponding Author:

Maite Mascaró ${ }^{2,3}$

Puerto de Abrigo S/N, 97356 Sisal, Yuc., Mexico

Email address:mmm@ciencias.unam.mx

\section{Abstract}

Finding new alternatives to traditional live preys such as Artemia and rotifers, which do not always promote optimal fish growth and survival, is required for the successful aquaculture of highly specialized predatory species, including seahorses. The present study assessed the nutritional value of an interesting marine amphipod (Paryhale hawaiensis), and evaluates through a feeding trial its potential use as a natural prey for 10-months lined seahorse, Hippocampus erectus. P. hawaiensis showed high levels of valuable lipids (20.4-26.7\% on dry matter basis) and polyunsaturated fatty acids (PUFAs) (26.4-41\% of total FAs), including the long-chain PUFAs (LC-PUFAs) arachidonic acid (ARA) (2.9-7.7\%), eicosapentaenoic acid (EPA) (4.3-6.5\%) and docosahexaenoic acid (DHA) (2.1-6.2\%). A comparison between wild-captured and cultured amphipods revealed a significant improvement of the amphipod FA profile in terms of DHA\%, total omega-3 (n3) FAs 
36

37

38

39

40

41

42

43

44

45

46

47

48

49

50

51

52

53

54

55

56

57

58

59

60

61

62

63

64

65

66

67

68

69

70

71

72

and $\mathrm{n} 3 / \mathrm{n} 6$ ratio when employing both a conventional amphipod culture based on a commercial shrimp diet, and, to a lesser extent, a large $(3500 \mathrm{~L})$ biofloc system. Seahorses fed with frozen/wild amphipods, either singly or in combination with Artemia enriched with Super Selco ${ }^{\circledR}$ (INVE Aquaculture, Belgium) for 57 days, substantially improved seahorse growth and FA profiles in terms of ARA, EPA and DHA\%, including index associated to marine sources, such as $\Sigma \mathrm{n} 3$ and n3/n6, compared to a diet based solely on enriched Artemia. These results support the use of marine amphipods as an alternative food organism for juvenile $H$. erectus and suggest a potential use for general marine aquaculture.

\section{Introduction}

Live food organisms are indispensable for the early culture of many marine species of commercial interest, including marine ornamentals (Olivotto et al., 2011, 2017a; Southgate, 2019). Due to the predatory nature of some species, live food stimulates a better feeding response compared to inert feeds, in addition to being more easily digested and assimilated (Conceição et al., 2010). The ideal live foods are fundamentally the preys a particular species encounter in nature and these often include small crustaceans such as copepods, amphipods and decapods (Olivotto et al., 2017b). The production of natural food organisms is, unfortunately, laborious and expensive, at best, and unsuccessful for most species (Southgate, 2019). The capture of live food organisms from the wild provides a viable alternative to captive propagation. Notwithstanding its cost-effectiveness, this practice is subject to seasonal availability and susceptible to the undesired introduction of pathogens and pests (Cohen and Valenti, 2019).

Because of their relatively easy production and cost, Artemia sp. and rotifers are the most commonly used live food organisms (Southgate, 2019). These preys are not the natural prey of marine fish, but they are widely used and with relative success (Bengtson, 2003). One of their main limitations is that they do not always satisfy the nutritional requirements of all organisms (Sorgeloos et al., 2001). "Enriching" these preys with formulations such as oil emulsions rich in essential FAs (EFAs) or microalgae, may overcome nutritional deficiencies; but even implementing this costly practice, they are often inadequate for the culture of many species, including seahorses (Segade et al., 2016; Randazzo et al., 2018; Planas et al., 2020).

In the last years, marine amphipods have received increasing attention as an alternative natural food. These benthic crustaceans can form large colonies $\left(>100000\right.$ individuals $\left.\mathrm{m}^{-2}\right)$ in natural or artificial aquatic habitats, such as coral reefs, seagrasses, seaweeds and biofoulings (Lourido et al., 2008; Vázquez-Luis et al., 2013; Navarro-Mayoral et al., 2020), where they constitute a major natural prey of small fish $(<30 \mathrm{~cm}$ standard length) and invertebrates (Woods, 2009). They are promising candidates both for intensive and extensive culture, as they can feed on a variety of foodstuffs, including decaying organic material and detritus (Guerra-García et al., 2016), and tolerate wide ranges of environmental parameters, such as temperature $\left(>20^{\circ} \mathrm{C}\right.$ range $)$ and salinity (> 20 psu range) (Takeuchi et al., 2003; Campbell et al., 2020). Although diet and environmental 
73 parameters can influence their nutritional value, they are generally rich in proteins (up to $60 \%$ of

$74 \mathrm{dw}$ ) and lipids (up to $20 \%$ on dry weight [dw] basis), including the PUFAs (over $50 \%$ of total FAs 75 in some species) EPA (over 20\% of total FAs) and DHA (up to $20 \%$ of total FAs) (Wang and Jeffs, 76 2014; Fernandez-Gonzalez et al., 2018; Jiménez-Prada et al., 2018). The few studies to assess and 77 develop potential culturing or harvesting techniques for aquaculture conducted so far are 78 promising (Guerra-García et al., 2016; Fernandez-Gonzalez et al., 2018; Xue et al., 2018; Vargas79 Abúndez et al., 2021). These include a recently published culture trial in biofloc systems 80 (Promthale et al., 2021).

81 Feeding trials to assess the potential use of amphipods as alternative feed conducted so far are 82 encouraging. As a partial fishmeal replacement, the Arctic amphipod (Themsto libellula) was 83 successfully incorporated into the diets of Atlantic salmon (Salmo salar) and Atlantic halibut 84 (Hippoglossus hippoglossus), substituting 40\% of fishmeal in diet (Suontama et al., 2007). 85 Gammarus species have also been of interest as amphipod meal (Harlığlu and Farhadi, 2018). 86 Both as live and frozen feed, several amphipod species have been successfully used to replace 87 traditional live foods in the culture of seahorses (Murugan et al., 2009; Vargas-Abúndez et al., 88 2018), octopus (Baeza-Rojano et al., 2013b) and cuttlefish (Baeza-Rojano et al., 2010).

89

90

91

92

93

94

95

96

97

98

99

100

101

102

103

104

105

106

107

108

109

110

According to traditional classification (Martin and David, 2001), Parhyale hawaiensis (Dana, 1853) is a gammarid amphipod with a worldwide, circumtropical distribution (WoRMS Editorial Board, 2020). It inhabits marine coastal habitats such as rocky beaches, estuaries and mangroves, where it readily forms dense aggregations of up to 7000 individuals $\mathrm{m}^{-2}$ (Poovachiranon et al., 1986; Paz-Ríos et al., 2013). Since the early 2000's, it has been attracting interest to the scientific community as a compelling crustacean model for biological research (Sun and Patel, 2019), due to their small size $\left(6.12-11.83 \mathrm{~mm}\right.$, total length), fast growth $\left(0.15 \mathrm{~mm}\right.$ day $\left.^{-1}\right)$, short life cycle (from newborn to adult in $50.9 \pm 5.8$ days), high fecundity (up to 35 embryos per female), translucent embryos and year-round reproduction (Vargas-Abúndez et al., 2021). It is amenable to experimental investigation and plenty of information and experimental tools, such as the complete genome and gene editing tools, are already available for this species (Kao et al., 2016; Sun and Patel, 2019). Propagation of $P$. hawaiensis under laboratory conditions is straightforward and well documented, with prospects for mass-scale aquaculture (Vargas-Abúndez et al., 2021). Taking advantage of its environmental tolerance, opportunistic behavior and detritivorous habits, $P$. hawaiensis could be an interesting candidate for mass production in biofloc systems. Biofloc technology represents an innovative approach for environmental-friendly, cost-effective intensive farming (Avnimelech, 2015; Ahmad et al., 2017).

The natural diet of most seahorse species is dominated by small crustaceans, primarily copepods, mysid shrimps, decapods and amphipods (Manning et al., 2019). However, amphipods stand out as the main food item in terms of frequency of occurrence, number or biomass ingestion for species such as $H$. breviceps, $H$. coronatus, $H$. erectus, $H$. guttulatus, $H$. hippocampus, $H$. patagonicus, $H$. subelongatus and $H$. whitei (Teixeira et al., 2001; Kendrick and Hyndes, 2005; Kitsos et al., 2008; 
111 Storero and González, 2008). Adult H. erectus, the lined seahorse, feed almost exclusively on 112 amphipods (mainly Gammarus muconathus), whereas juveniles on both amphipods (mainly 113 Ampithoe longimana) and copepods (Teixeira et al., 2001). Feeding trials conducted by the authors 114 demonstrated that this heavily traded species showed an increased feeding response when fed with 115 frozen amphipods (Elasmopus pectenicrus) compared to live Artemia (Vargas-Abúndez et al., 116 2018), confirming the potential of amphipods to overcome one of the main bottlenecks of seahorse 117 aquaculture, adequate feeding (Koldewey and Martin-Smith, 2010). Whether seahorse aquaculture 118 can meet the goal of providing a sustainable alternative to supply the traditional medicine, 119 aquarium and curio industries, highly depends on developing adequate live prey foods (Koldewey 120 and Martin-Smith, 2010).

121

122

123

124

125

126

127

128

Considering the aforementioned, the aim of the present study was (a) to assess the nutritional value of $P$. hawaiensis in relation to lipids and fatty acids (FA), and (b) to test their effects as a full or supplemental diet on growth, survival and FA profiles of juvenile $H$. erectus. Wild-captured amphipods were used in seahorse feeding trial. Additionally, and for the first time, amphipods were produced in a large-scale biofloc system and their nutritional value explored. The present study represents the first one evaluating the possible use of amphipods for seahorse feeding, testing the actual value of a new and promising amphipod species.

129

130

131

132

133

134

135

136

137

138

139

140

141

142

143

144

145

146

147

\section{Materials \& Methods}

\subsection{Ethics}

The present study was carried out under a permit by SEMARNAT No. SGPA/DGVS/12741/13 and strictly followed institutional protocols for the maintenance, manipulation, and sacrifice of the experimental animals according to certified criteria established by the Guide for the Care and Use of Experimental Animals in Research and Teaching of the Faculty of Superior Studies-Cuautitlán (http://www.cuautitlan.unam.mx/) at Universidad Nacional Autónoma de México. During the experiment, seahorse mortality was kept at zero and no apparent signs of stress were detected (i.e. changes in color, disease, lack of feeding or mobility).

\subsection{Foods of different source}

Amphipods (P. hawaiensis) were collected as previously described in Vargas-Abúndez et al. (2021). Specifically, they were collected both from outdoor flow-through systems in which amphipods grow freely at aquaculture facilities of the National Autonomous University of Mexico (UNAM) located in Sisal, Yucatán, México, and from green intertidal algae attached to rocks in Sisal beach. They are abundant in Sisal beach, from where they likely infiltrate the aquaculture systems. The animals were rinsed with fresh water and then some were immediately frozen at -80 ${ }^{\circ} \mathrm{C}$ for further lipid content and FA analysis, and at $-18{ }^{\circ} \mathrm{C}$ (commercial freezer) for use in the feeding trial. Hereafter, these amphipods are referred to as captured amphipods. The rest of the amphipods were acclimatized to laboratory conditions and held in an in-door $250 \mathrm{~L}$ tank with

Peer) reviewing PDF | (2021:03:59365:2:0:CHECK 14 Sep 2021) 
148

149

150

151

152

153

154

155

156

157

158

159

160

161

162

163

164

165

166

167

168

169

170

171

172

173

174

175

176

177

178

179

180

181

182

183

184

gentle aeration. Water in the tank was partially changed twice a week and maintained at $29.1 \pm 2.7$ ${ }^{\circ} \mathrm{C}$, salinity $35.9 \pm 5.5 \mathrm{ppt}$, $\mathrm{pH} 8.1 \pm 0.4, \mathrm{NO}_{2}^{-} 1.3 \pm 3.4 \mathrm{mg} \mathrm{L}^{-1}, \mathrm{NO}_{3}{ }^{-} 24.8 \pm 26.1 \mathrm{mg} \mathrm{L}{ }^{-1}$, $\mathrm{NH}_{3} / \mathrm{NH}_{4}^{+} 0.6 \pm 1.4 \mathrm{mg} \mathrm{L}^{-1}$. Plastic mesh was introduced in the tank as artificial substratum for the animals (Baeza-Rojano et al., 2013a; Vargas-Abúndez et al., 2021). Amphipods were fed daily with a commercial shrimp feed (Camaronina 35® Purina, Sonora, Mexico) (crude protein $350 \mathrm{~g}$ $\mathrm{kg}^{-1}$, lipids $80 \mathrm{~g} \mathrm{~kg}^{-1}$, ash $<100 \mathrm{~g} \mathrm{~kg}^{-1}$, fiber $<50 \mathrm{~g} \mathrm{~kg}^{-1}$, energy $21.6 \mathrm{~kJ} \mathrm{~g}^{-1}$, FA profile not available). Amphipods maintained this way were also used in the feeding trial and were labelled pellet-fed amphipods.

Simultaneously, amphipods were cultured in a biofloc system, following a modified protocol for shrimp biofloc systems described in Magaña-Gallegos et al. (2018), with some modifications. The culture took place in a large, out-door tank $(3500 \mathrm{~L})$ exposed to coastal climate conditions from May to December. Water in the tank was maintained at $27.2 \pm 2.1^{\circ} \mathrm{C}$, salinity $28.6 \pm 7.3 \mathrm{ppt}, \mathrm{pH}$ $8.4 \pm 0.1, \mathrm{NO}_{2}^{-} 0.7 \pm 0.9 \mathrm{mg} \mathrm{L}{ }^{-1}, \mathrm{NO}_{3}{ }^{-} 18.8 \pm 19.4 \mathrm{mg} \mathrm{L}{ }^{-1}, \mathrm{NH}_{3} / \mathrm{NH}_{4}{ }^{+} 0.6 \pm 1.1 \mathrm{mg} \mathrm{L}{ }^{-1}$. To stimulate the growth of nitrite-oxidizing bacteria, sodium nitrite $\left(\mathrm{NaNO}_{2}\right)$ was added at the beginning of the culture (Lara et al., 2016). To promote the generation of bioflocs, sugarcane molasses and wheat bran were added as carbon sources (Avnimelech, 2015). These were added at the beginning of the culture trial and every two weeks thereafter, until the biofloc volume reached $5 \mathrm{ml} \mathrm{L}^{-1}$ (biofloc volume was measured with Imhoff cones). When the biofloc volume decreased to less than $5 \mathrm{ml} \mathrm{L}^{-1}$ or total ammonia nitrogen (TAN) reached $1 \mathrm{mg} \mathrm{L}^{-1}$, carbon addition was resumed (Emerenciano et al., 2013). A high C/ N ratio of 20/1 was maintained, and water exchange was limited to compensate for evaporation. Sludge was removed occasionally from the tank by a central drain. The water was continuously aerated and pieces of plastic mesh were introduced as substrate for the amphipods. $P$. hawaiensis amphipods were introduced into the tank three weeks after the beginning of the culture. A commercial shrimp feed (Camaronina 35® Purina, Sonora, Mexico) was administered three times a week in excess, as an additional source of nitrogen and supplemental feed for the amphipods. This experimental group was labeled biofloc amphipods.

Artemia (ProAqua ${ }^{\circledR}$, Sinaloa, Mexico) was raised with wheat bran during the first 16 days and then, the last 6-8 days, with Spirulina sp. Prior to its use, it was enriched with Super Selco ${ }^{(I N V E ~}$ Aquaculture, Dendermonde, Belgium) in $1 \mathrm{~L}$ tanks for six hours at a concentration of $6 \mathrm{~mL} \mathrm{~L}^{-1}$. Enrichment period was chosen to avoid both FA autoxidation and FA retroconversion by Artemia (McEvoy et al., 1995; Nieves-Soto et al., 2021). Supporting this choice, preliminary observations indicated a significant increase in EPA and DHA percentage within six hours, as it was further confirmed by results herein (see section 3.1).

\subsection{Seahorses}

Wild pregnant $H$. erectus Perry, 1810 were captured at Laguna de Chelem, Yucatán, Mexico under a scientific license (SGPA/DGVS/12741/13) from the Mexican Ministry of the Environment and Natural Resources (SEMARNAT). Fish maintenance followed previously published methods by 
185

186

187

188

189

190

191

192

193

194

195

196

197

198

199

200

201

202

203

204

205

206

207

208

209

210

211

212

213

214

215

216

217

218

219

Vargas-Abúndez et al., 2018. After birth, juveniles were maintained in re-circulating holding tanks $(30 \mathrm{H} \times 28 \mathrm{~L} \times 18 \mathrm{~W} \mathrm{~cm}, 14 \mathrm{~L})$. Seawater was treated with mechanical $(25,10$ and $5 \mu \mathrm{m})$, biological and UV filtration. Water in the aquaria was maintained at $26 . \pm 0.5^{\circ} \mathrm{C}$ (mean \pm standard deviation), salinity $36.4 \pm 2.5 \mathrm{psu}$, $\mathrm{pH} 8.0-8.3, \mathrm{NO}_{2}^{-}<0.3 \mathrm{mg} \mathrm{L}^{-1}, \mathrm{NO}_{3}{ }^{-}<5 \mathrm{mg} \mathrm{L}^{-1}, \mathrm{NH}_{3} / \mathrm{NH}_{4}{ }^{+}<0.1 \mathrm{mg} \mathrm{L}^{-1}$ with a gentle aeration. A 12:12 photoperiod was kept throughout experiments. Polypropylene structures were placed in the aquaria to be used as holdfasts by the fish. Juvenile fish were fed three times a day (09:00 h, 14:00 h, 18:00 h) with live and frozen Artemia enriched with Super Selco ${ }^{\circledR}$ (INVE Aquaculture, Dendermonde, Belgium). At $50 \mathrm{~mm}$ standard length, fish were weaned from Artemia to frozen amphipods and then fed with a mix of the two foods, according to previous findings and culture recommendations (Lin et al., 2009; Vargas-Abúndez et al., 2018; Del Vecchio et al., 2019). Feces and uneaten food were siphoned out after feeding.

\subsection{Seahorse feeding trial}

Forty-eight $H$. erectus juveniles (21 males and 27 females) of ca. ten months old $(1.3 \pm 0.4 \mathrm{~g}$ wet weight, ranging from $0.72-2.48 \mathrm{~g}$ ) were randomly selected and individually tagged with a collar tag (Morgan and Bull, 2005). Fish were divided into 12 tanks of $15 \mathrm{~L}(30 \times 20 \times 30 \mathrm{~cm})$ with 4 fish in each tank, which were in turn evenly and randomly assigned to one of the three following dietary treatments (4 tanks per dietary group) (all diets frozen): i) amphipod diet: 100\% captured amphipods; ii) Artemia diet: 100\% enriched Artemia; iii) mixed diet: a 1:1 mix of the wild-captured amphipods and the Artemia diets.

Fish were fed in excess ( $25 \%$ of wet body weight per day) three times a day for 57 days. Water characteristics were maintained as previously described for seahorses. Fish growth was assessed through individual wet weight, which was repeatedly measured in each individual at the beginning of the experiment (day 0) and at days 15, 30, 45 and 57 with an OHAUS Adventurer analytical balance. Fish growth among experimental groups was not influenced by animal gender, as shown by data exploration (for raw data see supplementary materials). For comparative purposes, the specific growth rate (SGR) for individuals of each experimental group was calculated as follows:

$$
\mathrm{SGR} \%=((\ln \mathrm{Wf}-\ln \mathrm{Wi}) / \mathrm{t}) \times 100
$$

where Wf is the final wet weight, Wi, the initial wet weight, and $\mathrm{t}$, the number of days. Survival was recorded daily. At the end of the experiment (day 57) fish were euthanized by quick submersion in a mix of ice and water (hypothermia) and stored at $-80{ }^{\circ} \mathrm{C}$ for further FA acid analysis.

\subsection{Lipid content and fatty acid analysis}

To assess the nutritional value of amphipods, lipid content and FA analyses were conducted on samples of captured, biofloc (which treatment included shrimp food) and exclusively pellet-fed

amphipods. As a control group to the FA analyses, enriched Artemia was included. Once harvested 
220 from the different sources, amphipod samples were rinsed with freshwater and sieved through a $221710 \mu \mathrm{m}$ mesh; retained juveniles and adults were used for the analyses.

222 Samples were minced, freeze-dried and homogenized in liquid nitrogen with a commercial 223 blender. Lipid extraction was carried out based on Folch extraction procedure with 224 dichloromethane/methanol (2:1 v/v) (Folch et al., 1987). Extracts were saponified with 20\% $225 \mathrm{KOH}:$ Methanol (w/v) and FAs were obtained from the saponifiable fraction $(\mathrm{pH}=1-2)$ using 226 hexane as solvent. FAs were esterified with 10\% BF3 in methanol (Fluka 15716) for 60 min at 80 $227{ }^{\circ} \mathrm{C}$ and FA methyl esters (FAME) were obtained. FAME were separated and quantified by gas 228 chromatography using a Perkin Elmer Clarus 500 gas chromatograph (GC) equipped with a flame 229 ionization detector (FID), and a Phenomenex Zebron ZB-WAX capillary column (20 m length, $2300.18 \mathrm{~mm}$ i.d., $0.18 \mu \mathrm{m}$ film thickness). Hydrogen was used as the carrier gas at a flow rate of 40 $231 \mathrm{~mL} \mathrm{~min}{ }^{-1}$. The column temperature was programmed to increase from 40 to $200{ }^{\circ} \mathrm{C}$ at a rate of 20 $232{ }^{\circ} \mathrm{C} \mathrm{min}-1$ and from 200 to $250{ }^{\circ} \mathrm{C}$ at a rate of $2.5{ }^{\circ} \mathrm{C} \mathrm{min}{ }^{-1}$, whereas injector and detector 233 temperatures were set at 280 and $250{ }^{\circ} \mathrm{C}$, respectively. Individual components were identified 234 according to their retention times using analytical standards (Supelco ${ }^{\circledR} 37$ Component FAME 235 Mix, catalog no. 47885-U) as reference. Individual FA concentrations were expressed as 236 percentages of the total FA composition.

237 Fatty acid determinations were performed on seahorses once at the end of the trial. Six whole fish 238 samples per experimental group were randomly selected from previously sacrificed fish, and 239 analyzed in duplicate. Samples were minced, freeze-dried and homogenized in liquid nitrogen with 240 a commercial blender prior to analysis. In order to compare the FA profile of samples from 241 different foods and seahorses, the following indices were calculated: total saturated FAs ( $\Sigma$ SFA),

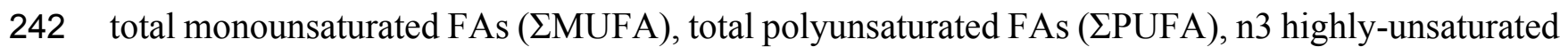
243 FAs (n3 HUFA; = C20:3n3 + C20:5n3 + C22:6n3), total n3 FAs $(\Sigma n 3)$, total n6 FAs $(\Sigma n 6)$, n3/n6, 244 DHA/EPA and EPA/ARA.

\section{2.6. Statistical analysis}

246 Statistical differences in total lipid content among amphipods of different source (captured 247 amphipods $[n=2]$, biofloc amphipods $[n=3]$ and pellet-fed amphipods $[n=3]$ ) were analyzed by 248 a one-way ANOVA. The statistical software package Prism5 (GraphPad Software) was used for 249 this analysis.

250 Variations in the FA composition between sources of food and seahorses fed with three different 251 diets were assessed by means of Principal Coordinate Analyses (PCoA). Whitaker's association 252 index ( $D_{9}$; Legendre and Legendre, 1998; Borcard et al., 2011) was applied to the data, expressed 253 as proportions of the total FA content in each sample in order to obtain a resemblance matrix with 254 dissimilarity measures between every pair of samples. Non-metric Dimensional Scaling (nMDS) 255 was used to compare the index values calculated to characterize the FA profiles of both foods and 256 seahorses. In this case, the Gower coefficient $\left(\mathrm{S}_{15}\right.$; Legendre and Legendre, 1998) was used to 
257

258

259

260

261

262

263

264

265

266

267

268

269

270

271

272

273

274

275

276

277

278

279

280

281

282

283

284

285

286

287

288

289

290

291

292

293

calculate multivariate distances between samples. Both the 2D and 3D configurations were obtained together with Kruskall's stress coefficient (Clarke et al., 2014) and the best was selected on the basis of stress criteria described in Legendre and Legendre (1998).

Multiple ANOVAs with permutations (Anderson, 2001) were used to distinguish differences in FA composition and indices related to food source and seahorse diet from random noise. In the first case, the underlying model was a one-way ANOVA with food source as a fixed factor with 4 levels: captured amphipods $(n=4)$, biofloc amphipods $(n=3)$, pellet-fed amphipods $(n=3)$ and enriched Artemia $(\mathrm{n}=2)$. The underlying model in the second case had seahorse diet as a fixed factor with 3 levels (amphipod, Artemia and a mixed diet), individual seahorses as a random factor nested within each level diet $(b=6)$, and $n=2$ replicate subsamples of every individual. Permutations of residuals under the reduced model (9999) were used to generate empirical distributions of pseudo- $F$ values under the null hypotheses (Anderson et al., 2017). Post hoc comparisons were applied following a similar procedure after the main test indicated significant differences $(p<0.05)$ between at least two centroids. Multivariate procedures were carried out using PRIMER 7 and PERMANOVA + for PRIMER.

Changes in seahorse wet weight through time was evaluated through regression analysis adjusting a mixed linear model (GLMM) with diet as a fixed factor (3 levels: amphipod diet, Artemia diet and mixed diet) and time (days) as a continuous variable. Preliminary data exploration showed that data did not comply to homoscedasticity (i.e. dispersion in seahorse weight increased as mean weight increased) or independence (i.e. seahorse weight was repeatedly measured on individuals through time). To ensure the reliability on the estimated coefficients and standard errors and pvalues obtained (Zuur et al., 2007), the model was adjusted with a generalized least-square procedure through restricted maximum likelihood and incorporated correlation and variance structures. The intercepts and slopes of linear equations corresponding to the three diets were compared with t-tests using the residual standard error estimated by the model. Different slopes would indicate different seahorse growth rates $\left(\mathrm{mg} \mathrm{day}^{-1}\right)$, irrespective of seahorse initial weights. The goodness of fit of the model was validated by visual inspection of residuals (Montgomery and Peck, 1992; Zuur et al., 2007). The R libraries nlme (Pinheiro et al., 2020) and ggplot2 (Wickham, 2016) were used to adjust the GLMM and generate the graphic visualization.

\section{Results}

\subsection{Foods of different source}

Biofloc and pellet-fed amphipods showed higher total lipid contents $(\% \mathrm{dw})(26.7 \pm 1.3 \%$ and $25.5 \pm 3.5 \%$ lipids, respectively) compared to captured amphipods $(20.4 \pm 0.8 \%)$, yet these were not statistically significant $(F=4.56 ; p=0.07)$. Table 1 shows the FA composition of all food sources. Multivariate analysis on the FA composition of food sources showed an effective reduction of dimensionality with the first and second principal coordinates containing $80 \%$ of the total variation in the data (Fig. 1; Supplemental Table 1). Samples from captured amphipods were

Peer] reviewing PDF | (2021:03:59365:2:0:CHECK 14 Sep 2021) 
294 located to the right-hand side of the ordination map and were associated with high contents of oleic 295 (C18:1n9c/t), arachidonic (C20:4n6), dihomo-gamma-linoleic (C20:3n6), pentadecylic (C15:0), 296 lauric (C12:0) and margaric (C17:0) acids. By contrast, samples from Artemia, pellet-fed and 297 biofloc amphipods were high in docosahexaenoic (C22:6n3), stearic (C18:0) and docosadienoic 298 (C22:2) acids and were located to the left-hand side of the map (Fig. 1). Artemia and biofloc 299 amphipods had the highest contents of linoleic (C18:2n6c), palmitoleic (C16:1) and alpha300 linolenic $(\mathrm{C} 18: 3 \mathrm{n} 3)$ acids, followed by captured and pellet-fed amphipods (see Supplemental 301 Table 1 for details on the contribution of each descriptor to the linear combinations of the first 302 three principal coordinates).

303 Results of the MANOVA revealed significant differences in FA composition of foods related to 304 its source ( $p$ seudo- $F=7.51 ; p<0.001 ; 9626$ unique permutations; Table 2 ), and clearly separated wild-captured amphipods from biofloc and exclusively pellet-fed amphipods (pseudo- $F=2.54$ and $3.17 ; p<0.05 ; 45$ unique permutations, respectively). However, samples from Artemia could not be statistically distinguished from any of the other groups (pseudo- $F$ from 2.53 to $3.5 ; p$ from 0.07 309 to $0.1 ; 10$ to 15 unique permutations), probably due to its low number of replicates ( $\mathrm{n}=2$; Table 2).

310

311

312

313

314

315

316

317

318

319

320

321

322

323

324

325

326

327

328

329

330

The 3D nMDS configuration map of several indices describing the FA profiles of food sources had a stress coefficient of 0.02 . A $2 \mathrm{D}$ projection of this configuration showed that captured amphipods had high values of $\Sigma$ SFA and $\Sigma$ MUFA, followed by biofloc and pellet-fed amphipods (Fig. 2). Artemia samples had the highest values of $\Sigma$ PUFA and $\Sigma \mathrm{n} 6$, whereas pellet-fed amphipods had the highest values of EPA/ARA and $\Sigma \mathrm{n} 3$ (Fig. 2; see Supplemental Table 2 for details on the multiple correlation coefficients of descriptors with the first three ordinal axes). Here again, the MANOVA procedures statistically distinguished captured amphipods from biofloc and pellet-fed amphipods ( $p s e u d o-F=1.78$ and $3.56 ; p<0.05 ; 35$ unique permutations, respectively), but was unable to find significant differences between the latter ( $p s e u d o-F=4.19 ; p=0.09 ; 10$ unique permutations, Table 3). Artemia samples were again statistically similar to all the other groups (pseudo- $F$ from 2.49 to 3.64 ; $\mathrm{p}$ from 0.07 to $0.1 ; 10$ to 15 unique permutations; Table 3).

\subsection{Seahorses}

All the animals used for the present study survived until the end of the experiment. The GLMM showed a significant interaction term indicating that linear equations describing fish growth differed depending on the diet $(F=46.2 ; p<0.0001)$. Further comparisons of the regression coefficients showed statistically similar intercepts but different slopes in the corresponding linear equations (Table 4). Results demonstrated that captured amphipods in the diet, both solely (amphipod diet: $13 \pm 2 \mathrm{mg} \mathrm{day}^{-1} ; 0.8 \pm 0.3 \%$ SGR) and in combination with Artemia (mixed diet: $11 \pm 1 \mathrm{mg} \mathrm{day}^{-1} ; 0.67 \pm 0.43 \%$ SGR), significantly increased the growth rate of juvenile seahorses compared to Artemia alone ( $0.057 \pm 0.002 \mathrm{mg} \mathrm{day}^{-1} ; 0.04 \pm 0.18 \%$ SGR; Fig.3). Moreover, results showed that seahorses fed the Artemia diet had growth rates statistically indistinguishable from 
331 332

zero. The GLMM significantly improved (L.ratio $=497.5 ; p<0.001$ ) by adding an exponential variance structure of the form:

$$
\sigma^{2}=R S E^{2} \times \exp ^{\left(2 \delta_{i} \text { Day }\right)}
$$

where RSE is the residual standard error, $\delta$ is the parameter for each $i$ level of diet. This allowed for the variance associated to each treatment at each experimental day to be estimated (Table 5). These results indicate that inclusion of amphipods in the diet made seahorse weight more variable and dispersion increased with experimental days.

Table 6 shows the FA composition of seahorses at the end of the dietary treatment. PCoA on FA composition of seahorse tissue showed that $80.5 \%$ of total variation in the data was contained in the first and second principal coordinates. Ordination clearly separated samples from seahorses fed diets that included amphipods to the right-hand side, from those fed Artemia alone to the lefthand side of the map (Fig. 4). Eigenanalysis showed that the former were samples with high content of eicosatrienoic (C20:3n3), lauric (C12:0) and myristic (C14:0) and to a lesser extent of eicosenoic (C20:1n9), alpha-linolenic (C18:3n3), eicosapentaenoic (C20:5n3), tridecylic (C13:0), palmitoleic (C16:1) and pentadecylic (C15:0) acids. These samples, however, were low in linoleic (C18:2n6c), gamma-linoleic (C18:3n6), stearic (C18:0), lignoceric (C24:0) and behenic (C22:0) acids. The opposite was true for seahorses fed with Artemia. The second coordinate separated samples on the top of the map (mostly from the amphipod diet) with higher contents of oleic acid $(\mathrm{C} 18: 1 \mathrm{n} 9 \mathrm{c} / \mathrm{t})$, whereas those at the bottom (mostly from the mixed diet) were high in dihomogamma-linoleic (C20:3n6), arachidonic (C20:4n6) and docosahexaenoic (C22:6n3) acids (Fig. 4; see Supplemental Table 3 for details on the contribution of each descriptor to the linear combinations of the first four principal coordinates).

Results of the MANOVA confirmed significant differences in FA content associated to seahorse $\operatorname{diet}($ pseudo- $F=15.0 ; p<0.001 ; 9920$ unique permutations, Table 7). No significant differences were found between subsamples of seahorse tissue ( $p$ seudo- $F=1.19 ; p=0.28 ; 9907$ unique permutations), indicating that the method for the determination of FA content was highly consistent. Paired comparisons of centroids showed that the diet based on Artemia resulted in seahorses with a significantly different FA content compared to those fed with either the amphipod or mixed diets (pseudo- $F=6.32$ and 3.67; both $p<0.01 ; 461$ and 462 unique permutations, respectively). Statistical differences were also found between the two diets containing amphipods (pseudo- $F=1.94 ; p<0.05 ; 461$ and 462 unique permutations, Table 7).

The nMDS applied on indices describing the FA profiles also successfully separated tissue samples from seahorses fed with different diets (3D Stress $=0.04$; Fig. 5). The permutational MANOVA showed that FA profiles differed significantly depending on diet ( $p$ seudo- $F=7.63 ; p<0.001 ; 9913$ unique permutations; Table 8), whereas variation amongst individual seahorses subjected to the same diet were not larger than those expected by chance ( $p s e u d o-F=1.26 ; p=0.24 ; 9914$ unique 
367

368

369

370

371

372

373

374

375

376

377

378

379

380

381

382

383

384

385

386

387

388

389

390

391

392

393

394

395

396

397

398

399

400

401

402

403

permutations). Here again, the FA profile of seahorses fed with Artemia was statistically different from the amphipod and mixed diets (pseudo- $F=4.23$ and 2.26; both $p<0.01$; both 462 unique permutations, respectively), but these two were not statistically distinguishable (pseudo- $F=1.81$; $p=0.06 ; 462$ unique permutations). The 3D configuration projected on two dimensions showed that samples from the amphipod and mixed diets had high $\Sigma$ n3, n3HUFA, EPA/ARA and $\Sigma$ MUFA values, whereas those from Artemia had high DHA/EPA and $\Sigma$ n6 (Fig. 5). The n3/n6 ratio was higher in the former than in the latter. The amphipod diet resulted in slightly higher $\Sigma$ MUFA, whereas the mixed diet had higher $\Sigma$ PUFA (Fig.5); but these differences can only be considered marginally significant (see Supplemental Table 4 for details on the multiple correlation coefficients of descriptors with the first three ordinal axes).

\section{Discussion}

\subsection{Nutritional value of $P$. hawaiensis from different production sources}

Results in the present study revealed that captured $P$. hawaiensis contains high levels of lipids ( $20.4 \pm 0.8 \%$ of $\mathrm{dw}$ ), with a FA profile suitable for feeding $H$. erectus juveniles, namely rich in the EFAs ARA, EPA and DHA. Interestingly, amphipod production based both on the use of a large biofloc system and a small in-door tank with commercial pellets tended to increase the lipid content $(26.7 \pm 1.3 \%$ and $25.5 \pm 3.5 \%$, respectively). This was true despite the relatively low lipid content of the commercial feed used ( $80 \mathrm{~g} \mathrm{lipid} \mathrm{kg}^{-1}$ ) and the typically low content of bioflocs (1.68.3\% lipids) (Ahmad et al., 2017; Magaña-Gallegos et al., 2018; Sgnaulin et al., 2018). There is a limited number of studies analyzing lipid content in the context of aquaculture to compare with, but these lipid levels are slightly higher than those found in amphipods harvested from an offshore aquaculture farm (13\%) (Fernandez-Gonzalez et al., 2018), shrimp biofloc ponds (4.7-6.3\%), rivers (7.5-13\%) (Kolanowski et al., 2007), different marine areas (5.1-19.15\%) (Baeza-Rojano et al., 2014; Jiménez-Prada et al., 2018), as well as in other commonly used live food organisms, such as mysids (6.7-8.0\%) (Planas et al., 2020) and copepods (11.3-12.4\%) (Wang et al., 2014). The optimal dietary lipid levels for seahorses are still unknown, but researchers agree that beyond lipid content, a well-balance FA fraction plays a pivotal role in seahorse nutrition (Faleiro and Narciso, 2010; Segade et al., 2016; Planas et al., 2020).

Amphipods from all three sources (captured, biofloc and pellet-fed amphipods) showed valuable levels of PUFAs (26.38-41\%), almost as high as SFAs (39.6-41.7\%). These levels are similar to those reported for the marine gammarid Hyalella media collected from the same coastal area (Baeza-Rojano et al., 2013b) and others from the strait of Gibraltar (Baeza-Rojano et al., 2014); but lower than highly nutritious organisms such as copepods (Zhang et al., 2015), mysids (Schlechtriem et al., 2008; Herrera et al., 2010) and long-time enriched Artemia (Planas et al., 2017), particularly regarding DHA and n3/n6 ratio. In contrast to enriched Artemia, that showed a FA profile rich in $\Sigma$ n6 and linoleic acid typical of freshwater organisms (Sargent et al., 1999), amphipods were characterized by high contents in SFAs and MUFAs. Amphipods did not

Peerj reviewing PDF | (2021:03:59365:2:0:CHECK 14 Sep 2021) 
404 dramatically differ in terms of the presence of nutritionally relevant FAs, such as ARA, EPA and 405 DHA, compared to Artemia. However, both PCoA and nMDS ordinations clearly separated 406 amphipods from Artemia, suggesting that amphipods used herein could present a more "marine 407 profile", similar to that in studies of amphipods from littoral areas (Woods, 2009; Jiménez-Prada 408 et al., 2018; Alberts-Hubatsch et al., 2019). This was especially true for pellet-fed amphipods, 409 which showed the highest values of $\Sigma \mathrm{n} 3$, n3 HUFAs, n3/n6, DHA, DHA/EPA and EPA/ARA. 410 DHA, along with ARA and EPA, are important components of cellular membranes and precursors 411 of bioactive molecules involved in essential metabolic and physiological processes (Tocher, 2003). 412 These FAs are considered essential for marine fish and shrimp nutrition, as they have limited 413 enzymatic capacity to synthesize them de novo (Tocher et al., 2003). Required absolute values for 414 these nutrients are species-specific, but they are generally needed at levels around 1\% dry weight 415 of diet (National Research Council (NRC), 2011). Besides providing sufficient amounts of these 416 FAs to meet requirements, it is also important to optimize their relative proportions, as their 417 essential functions can be influenced by the presence and relative amounts of other FAs (Izquierdo 418 and Koven, 2011). For example, in Atlantic salmon, addition of EPA to a DHA rich diet enhanced 419 DHA tissue retention and fish growth, whereas addition of ARA did not enhance growth but 420 reduced DHA retention (Glencross et al., 2014). Although captured amphipods in the present study 421 showed higher ARA contents (Fig. 1 and 2), DHA was highest in both biofloc and pellet-fed 422 amphipods, suggesting a better FA balance in these cultured amphipods. Absolute FA amounts 423 were not quantified in the present study but, with ARA, EPA and DHA contents ranging from 2.9 424 to $9.1 \%$ of total FAs, $P$. hawaiensis could fulfill such dietary requirements (NRC, 2011; Zhang et 425 al., 2015).

426

427

428

429

430

431

432

433

434

435

436

437

438

439

440

441

442

The improved FA profile of pellet-fed amphipods, and to a lesser extent of biofloc amphipods, was not surprising, given that the commercial shrimp feed used is expected to meet the nutritional requirements of penaeid shrimps (Martinez-Cordova et al., 2003). The main ingredient of the feed is fishmeal (Chávez-Sánchez, 1993), which may contain ideal sources of PUFAs and amino acids for aquafeeds (Vargas-Abúndez et al., 2019). Whilst both biofloc and pellet-fed amphipods were fed the commercial shrimp diet, it is likely that the biofloc culture provided an additional source of food for the amphipods, hence explaining the slight differences in FA composition between biofloc and pellet-fed amphipods. $P$. hawaiensis is a detritivorous species and, as an opportunistic grazer, it is expected to feed efficiently on different floc particles. Amphipod gut content was not analyzed but amphipods introduced into the biofloc system changed markedly in color compared to pellet-fed amphipods, turning from almost translucence to a dark brown body with a green belly after a few days (personal observations), possibly as a result of microalgae and biofloc ingestion.

As previously reported for a similar biofloc setup (Magaña-Gallegos et al., 2018), the FA composition of the biofloc particles in the present study was probably low in EPA and DHA. However, the actual nutritional value of bioflocs can vary according to a number of factors, including biofloc particle size, carbon source, biofloc maturation, floc density, food preference by cultured animals and their ability to ingest and digest the different biofloc particles (Ahmad et al., 
443 2017; Magaña-Gallegos et al., 2018; Promthale et al., 2021). Results herein are insufficient to 444 ascertain specific causes, but indicate that resulting biofloc amphipods present a FA profile highly 445 suitable for applications in marine aquaculture, i.e. with significant amounts of ARA, EPA and 446 DHA and better n3/n6, DHA/EPA, EPA/ARA ratios compared to enriched Artemia. Further 447 research should assess other nutrients such as proteins and their amino acid constituents, as they 448 also play foremost important roles in fish growth and development (D’Abramo, 2019).

449

450

451

452

453

454

455

456

457

458

459

460

461

462

463

464

465

466

467

468

469

470

471

472

473

474

475

476

477

478

479

480

\subsection{Effect of amphipods on the seahorse growth and fatty acid profile}

The use of captured amphipods substantially enhanced the growth of juvenile seahorses when used both solely (amphipod diet) or in combination with enriched Artemia (mixed diet) (Fig. 3). Whilst all individuals in all dietary treatments survived throughout the 57-day trial, the use of enriched Artemia as the only food source did not promote seahorse growth, since no significant change in the wet weight in animals in this treatment could be demonstrated. Results similar to these have been previously reported in other H. guttulatus adults (Palma et al., 2008). It is well documented that Artemia is not an adequate prey for many seahorse species due to nutritional deficiencies, poor digestibility and absorption (Payne and Rippingale, 2000; Blanco et al., 2015; Randazzo et al., 2018). Despite its limitations, Artemia is largely used given its extensive availability (Sorgeloos et al., 2001; Bengtson, 2003; Olivotto et al., 2008; Del Vecchio et al., 2019; Southgate, 2019; Planas et al., 2020).

In contrast to Artemia, amphipods are a natural prey for seahorses and other marine organisms (Manning et al., 2019). Several authors have found food preferences in seahorses over natural preys, such as mysids and copepods (Buen-Ursua et al., 2015, Blanco and Planas, 2015), although depending on the stage of development. Regarding amphipods, a previous study by the authors (Vargas-Abúndez et al., 2018), found very different ingestion rates in H. erectus juveniles (7.7-96 mm standard length) when comparing amphipods and Artemia diets. With frozen amphipods (E. pectenicrus), seahorses ingested $4.1 \pm 1.7 \%$ of its wet body weight within 12 minutes, whereas with live Artemia seahorses ingested equivalent biomass only after 90 minutes. In the present study, ingestion rates were not measured, but based on the previous one, it is likely that fish ingested a higher amphipod biomass compared to that of Artemia, thereby partially explaining the increased growth in the two diets that contained amphipods. These results are encouraging and consistent with previous observations on other marine organisms kept under controlled conditions. In a trial with Octopus maya, live marine gammarids induced a higher growth rate $\left(6.9 \pm 0.2 \%\right.$ day $^{-}$ $\left.{ }^{1}\right)$ and survival $(92.2 \pm 6.8 \%)$ compared to adult Artemia $\left(4.8 \pm 0.2 \%\right.$ day $^{-1}$ growth and $74.5 \pm$ $23.8 \%$ survival) and freshwater gammarids $\left(5.0 \pm 0.3 \%\right.$ day $^{-1}$ growth and $41.2 \pm 21.2 \%$ survival $)$ (Baeza-Rojano et al., 2013b). Both gammarids and caprellids have been recognized as nutritionally adequate prey for cuttlefish hatchlings (Baeza-Rojano et al., 2010). However, gammarids induce a better feeding response and consequently growth and survival in cuttlefish, compared to caprellids, due to differences in behavior (Baeza-Rojano et al., 2010). In Atlantic salmon and Atlantic halibut, amphipod meal successfully replaced up to $40 \%$ of fish meal in compound diets, 
481 with no negative effects on feed conversion ratio, dry matter digestibility, protein digestibility and 482 muscle composition (Suontama et al., 2007).

483 The improved growth of $H$. erectus fed either the amphipod or the mixed diet could also be related 484 to the nutritional value of the diets, particularly with regard to FAs. The nutritional requirements 485 of seahorses are still unknown, but high levels of PUFAs, particularly of the LC-PUFAs ARA, 486 EPA and DHA, seems to be determinant for seahorse growth and survival (Faleiro and Narciso, 487 2010; NRC, 2011). In the wild, seahorses mostly consume small crustaceans such as copepods, 488 mysid shrimps and amphipods (Teixeira et al., 2001; Manning et al., 2019), known to be rich 489 sources of LC-PUFAs (Woods, 2009; Guerra-García et al., 2014; Alberts-Hubatsch et al., 2019).

In the present study, both PCoA and nMDS ordination methods applied on their respective FA profiles (Fig. 4 and 5) clearly separated samples of seahorses fed either amphipod diets from those fed Artemia, and this separation was statistically distinguished from random noise. Artemia was enriched with PUFAs (Super Selco ${ }^{\circledR}$ ) and thus resulted in higher PUFA percentages with respect to both amphipod diets. However, the higher PUFA content was mainly the result of increased linoleic acid (C18:2n6c), whereas nutritionally relevant markers such as, ARA, EPA and DHA were found in similar percentages in all three diets. Linoleic acid is characteristic of terrestrial plants and consequently of non-marine organisms such as Artemia, especially when fed ingredients of terrestrial origin (Balachandar and Rajaram, 2019). Linoleic acid is considered an EFA for freshwater fish, but not for marine fish (NRC, 2011). In the present study, Artemia was raised with wheat bran, which could have increased the abundance of this FA. Interestingly, the higher PUFA content in Artemia did not translate into increased levels of PUFAs in the seahorses. On the contrary, despite similar ARA, EPA and DHA compositions amongst all three diets, seahorses fed enriched Artemia showed lower percentages of these FAs. This trend became more clearly evidenced by the nMDS projection applied to indices describing the FA profile, where samples of seahorses fed either amphipod diets showed closer association to vectors representing $\Sigma \mathrm{n} 3, \mathrm{n} 3$ HUFAs, EPA/ARA and $\Sigma$ MUFAs, whereas those from Artemia were closer to $\Sigma$ n6 and DHA/EPA (Fig. 5). In fact, the higher $n 6$ percentage detected in the Artemia diet was reflected in the seahorse $\mathrm{n} 6$ percentage and, consequently, in a substantial reduction in the $\mathrm{n} 3 / \mathrm{n} 6$ ratio amongst seahorses fed with this diet. Marine fish have higher requirements of $\mathrm{n} 3$ FAs than of n6, and, as stated earlier, optimal ratios tend to be high due to competitive interactions in FA biosynthesis (Faleiro and Narciso, 2010; NRC, 2011). $\mathrm{n} 3 / \mathrm{n} 6$ ratios of about $2.5-3.5$ are common in natural prey ingested by seahorses (Zhang et al., 2015; Segade et al., 2016; Planas et al., 2020). In egg, newborn and juvenile seahorses, this ratio ranges from 1 to 16 , being generally higher in earlier developmental stages (Saavedra et al., 2014; Segade et al., 2016; Planas et al., 2020). In newborn H. erectus, improved growth with an $\mathrm{n} 3 / \mathrm{n} 6$ ratio of 2.5 was achieved with the use of calanoid copepods collected from fish ponds (Zhang et al., 2015). Thus, the $\mathrm{n} 3 / \mathrm{n} 6$ ratio observed in the present study when using the amphipod diet $(0.97 \pm 0.17)$ was comparatively low but highly satisfactory for feeding late juveniles of $H$. erectus. 
519 A third element that could explain the better performance of the amphipod diets is digestibility. 520 Poor digestibility due to limited enzymatic capacity is a common issue in newborn and early stage 521 seahorses (Blanco et al., 2015; Novelli et al., 2016; Ofelio et al., 2018). However, it was suggested 522 that adult seahorses can display differences in the digestibility of zooplanktonic organisms (Corse 523 et al., 2015). The digestibility of amphipods has only been evaluated in Atlantic salmon and 524 Atlantic halibut compound diets, and it was comparable to the excellent digestibility of fish meal 525 and krill meal (Suontama et al., 2007). That brings the possibility that amphipods, as natural prey 526 of $H$. erectus, could be more efficiently digested and absorbed compared to Artemia. It may explain 527 why diets containing amphipods outperformed the Artemia diet despite small differences in key 528 nutrients (ARA, EPA and DHA). It remains unclear why seahorses fed exclusively Artemia did

529

530

531

532

533

534

535

536

537

538

539

540

541

542

543

544

545

546

\section{Acknowledgements}

548 The authors are grateful to Eduardo Cruz-Hernandez for conducting the seahorse feeding trial, 549 collecting and processing the corresponding data, and to Marcela Yamileth Lopez Noriega for 550 collecting and processing amphipod samples for fatty acid analysis. M. Sc. Iveth Gabriela

551 Palomino Albarrán and Patricia M. Balam Uc supplied live Artemia.

\section{References}

553 Ahmad, I., Babitha Rani, A.M., Verma, A.K., Maqsood, M., 2017. Biofloc technology: an 
554

555

556

557

558

559

560

561

562

563

564

565

566

567

568

569

570

571

572

573

574

575

576

577

578

579

580

581

582

583

584

585

586

587

588

emerging avenue in aquatic animal healthcare and nutrition. Aquaculture International 25, 1215-1226. https://doi.org/10.1007/s10499-016-0108-8

Alberts-Hubatsch, H., Slater, M.J., Beermann, J., 2019. Effect of diet on growth, survival and fatty acid profile of marine amphipods: Implications for utilisation as a feed ingredient for sustainable aquaculture. Aquaculture Environment Interactions 11, 481-491. https://doi.org/10.3354/aei00329

Anderson, M.J., 2001. A new method for non-parametric multivariate analysis of variance. Austral Ecology 26, 32-46. https://doi.org/10.1111/j.1442-9993.2001.01070.pp.x

Anderson, M. J. 2017. Permutational multivariate analysis of vari $\neg$ ance (PERMANOVA). Wiley StatsRef: Statistics Reference Online. Wiley.

Avnimelech, Y., 2015. Biofloc Technology, a Practical Guidebook, Third. ed. World Aquaculture Society.

Baeza-Rojano, E., Calero-Cano, S., Hachero-Cruzado, I., Guerra-García, J.M., 2013a. A preliminary study of the Caprella scaura amphipod culture for potential use in aquaculture. Journal of Sea Research 83, 146-151. https://doi.org/10.1016/j.seares.2013.04.014

Baeza-Rojano, E., Domingues, P., Guerra-García, J.M., Capella, S., Noreña-Barroso, E., Caamal-Monsreal, C., Rosas, C., 2013b. Marine gammarids (Crustacea: Amphipoda): a new live prey to culture Octopus maya hatchlings. Aquaculture Research 44, 1602-1612. https://doi.org/10.1111/j.1365-2109.2012.03169.x

Baeza-Rojano, E., García, S., Garrido, D., Guerra-García, J.M., Domingues, P., 2010. Use of Amphipods as alternative prey to culture cuttlefish (Sepia officinalis) hatchlings. Aquaculture 300, 243-246. https://doi.org/10.1016/j.aquaculture.2009.12.029

Baeza-Rojano, E., Hachero-Cruzado, I., Guerra-García, J.M., 2014. Nutritional analysis of freshwater and marine amphipods from the Strait of Gibraltar and potential aquaculture applications. Journal of Sea Research 85, 29-36. https://doi.org/10.1016/j.seares.2013.09.007

Balachandar, S., Rajaram, R., 2019. Influence of different diets on the growth, survival, fecundity and proximate composition of brine shrimp Artemia franciscana (Kellog, 1906). Aquaculture Research 50, 376-389. https://doi.org/10.1111/are.13882

Bengtson, D.A., 2003. Status of marine aquaculture in relation to live prey: past, present and future, in: Støttrup, J.G., McEvoy, L.A. (Eds.), Live Feeds in Marine Aquaculture, Wiley Online Books. pp. 1-16. https://doi.org/10.1002/9780470995143.ch1

Blanco, A., Planas, M., 2015. Mouth growth and prey selection in juveniles of the european long-snouted seahorse, Hippocampus guttulatus. Journal of the World Aquaculture Society 46, 596-607. https://doi.org/10.1111/jwas.12240 
589 Blanco, A., Planas, M., Moyano, F.J., 2015. Ontogeny of digestive enzymatic capacities in 590 juvenile seahorses Hippocampus guttulatus fed on different live diets. Aquaculture 591 Research 47. https://doi.org/10.1111/are.12806

592 Borcard, D., Gillet, F., Legendre, P. 2011. Numerical Ecology with R. Springer, NY, USA.

593 Buen-Ursua, S. M. A., Azuma, T., Arai, K., \& Coloso, R. M., 2015. Improved reproductive

594

595

596

597

598

599

600

601

602

603

604

605

606

607

608

609

610

611

612

613

614

615

616

617

618

619

620

621

622

623 performance of tiger tail seahorse, Hippocampus comes, by mysid shrimp fed singly or in combination with other natural food. Aquaculture International, 23(1), 29-43. https://doi.org/10.1007/s10499-014-9795-1

Campbell, H., Ledet, J., Poore, A., Harianto, J., \& Byrne, M., 2020. Resilience of the amphipod Hyale niger and its algal host Sargassum linearifolium to heatwave conditions. Marine Biology, 167(6), 72. https://doi.org/10.1007/s00227-020-03681-2

Chávez-Sánchez, M.C., 1993. El estado actual de la acuicultura en mexico y perfiles de nutricion y alimentacion (contd.), in: Martínez-Palacios, C.A., Chavez-Sánchez, M.C., Varsi, E. (Eds.), La Nutricion y Alimentacion En La Acuicultura de America Latina y El Caribe. FAO.

Clarke, K.R., Gorley, R.N., Somerfield, P.J., 2014. Change in marine communities: an approach to statistical analysis and interpretation, 3nd ed. PRIMER-E: Plymouth.

Cohen, F.P.A., Valenti, W.C., 2019. Opportunities and constraints for developing low-cost aquaculture of seahorses in mangrove estuaries. Aquaculture 502, 121-127. https://doi.org/10.1016/j.aquaculture.2018.12.031

Conceição, L.E.C., Yúfera, M., Makridis, P., Morais, S., Dinis, M.T., 2010. Live feeds for early stages of fish rearing. Aquaculture Research 41, 613-640. https://doi.org/10.1111/j.13652109.2009.02242.x

Corse, E., Valladares, S., Planas, M., Chamorro, A., Pintado, J., 2015. Analysis of the diet of the long-snouted seahorse Hippocampus guttulatus by $18 \mathrm{SrDNA}$ amplification of prey in faeces. Aquaculture Nutrition 21, 528-540. https://doi.org/10.1111/anu.12189

Dale, K., Falk-Petersen, S., Hop, H., Fevolden, S.E., 2006. Population dynamics and body composition of the Arctic hyperiid amphipod Themisto libellula in Svalbard fjords. Polar Biology 29, 1063-1070. https://doi.org/10.1007/s00300-006-0150-5

Del Vecchio, G., Otero-Ferrer, F., Pascual, C., Rosas, C., Simoes, N., Mascaró, M., 2019. Effect of starvation on survival and biochemical profile of newborn juvenile lined seahorses, Hippocampus erectus (Perry, 1810). Aquaculture Research 50, 3729-3740. https://doi.org/10.1111/are.14333

D’Abramo, L. 2019. Nutrition and feeds, in: Lucas, J.S., Southgate, P.C., Tucker, C.S. (Eds.), Aquaculture: Farming Aquatic Animals and Plants, 3rd Edition. John Wiley \& Sons Ltd, 
624

625

626

627

628

629

630

631

632

633

634

635

636

637

638

639

640

641

642

643

644

645

646

647

648

649

650

651

652

653

654

655

656

657

658

pp. 157-182.

Emerenciano, M., Cuzon, G., Arévalo, M., Miquelajauregui, M.M., Gaxiola, G., 2013. Effect of short-term fresh food supplementation on reproductive performance, biochemical composition, and fatty acid profile of Litopenaeus vannamei (Boone) reared under biofloc conditions. Aquaculture International 21, 987-1007. https://doi.org/10.1007/s10499-0129607-4

Faleiro, F., Narciso, L., 2010. Lipid dynamics during early development of Hippocampus guttulatus seahorses: Searching for clues on fatty acid requirements. Aquaculture 307, 5664. https://doi.org/10.1016/j.aquaculture.2010.07.005

Fernandez-Gonzalez, V., Toledo-Guedes, K., Valero-Rodriguez, J.M., Agraso, M.M., SanchezJerez, P., 2018. Harvesting amphipods applying the integrated multitrophic aquaculture (IMTA) concept in off-shore areas. Aquaculture 489, 62-69. https://doi.org/10.1016/j.aquaculture.2018.02.008

Folch, J., Lees, M., Sloane-Stanley, G.H., 1987. A simple method for the isolation and purification of total lipides from animal tissues. The Journal of Biological Chemistry 226, 497-509.

Glencross, B.D., Tocher, D.R., Matthew, C., Gordon Bell, J., 2014. Interactions between dietary docosahexaenoic acid and other long-chain polyunsaturated fatty acids on performance and fatty acid retention in post-smolt Atlantic salmon (Salmo salar). Fish Physiology and Biochemistry 40, 1213-1227. https://doi.org/10.1007/s10695-014-9917-8

Guerra-García, J.M., Hachero-Cruzado, I., González-Romero, P., Jiménez-Prada, P., Cassell, C., Ros, M., 2016. Towards Integrated Multi-Trophic Aquaculture: Lessons from Caprellids (Crustacea: Amphipoda). PLOS ONE 11, e0154776. https://doi.org/10.1371/journal.pone.0154776

Guerra-García, J.M., Tierno de Figueroa, J.M., Navarro-Barranco, C., Ros, M., SánchezMoyano, J.E., Moreira, J., 2014. Dietary analysis of the marine Amphipoda (Crustacea: Peracarida) from the Iberian Peninsula. Journal of Sea Research 85, 508-517. https://doi.org/10.1016/j.seares.2013.08.006

Harlığlu, M.M., Farhadi, A., 2018. Importance of Gammarus in aquaculture. Aquaculture International 26, 1327-1338.

Herrera, A., Gómez, M., Molina, L., Otero, F. and Packard, T., 2011. Rearing techniques and nutritional quality of two mysids from Gran Canaria (Spain). Aquaculture Research, 42: 677-683. https://doi.org/10.1111/j.1365-2109.2010.02786.x

Izquierdo, M., Koven, W., 2011. Lipids, in: Holt, G.J. (Ed.), Larval Fish Nutrition, Wiley Online Books. https://doi.org/10.1002/9780470959862.ch2 
659 Izquierdo, M.S., 1996. Essential fatty acid requirements of cultured marine fish larvae. 660 Aquaculture Nutrition 2, 183-191. https://doi.org/10.1111/j.1365-2095.1996.tb00058.x

661

662

663

664

665

666

667

668

669

670

671

672

673

674

675

676

677

678

679

680

681

682

683

684

685

686

687

688

689

690

691

692

693

Jiménez-Prada, P., Hachero-Cruzado, I., Giráldez, I., Fernández-Diaz, C., Vilas, C., Cañavate, J.P., Guerra-García, J.M., 2018. Crustacean amphipods from marsh ponds: A nutritious feed resource with potential for application in Integrated Multi-Trophic Aquaculture. PeerJ 1-27. https://doi.org/10.7717/peerj.4194

Kao, D., Lai, A.G., Stamataki, E., Rosic, S., Konstantinides, N., Jarvis, E., Di Donfrancesco, A., Pouchkina-Stancheva, N., Sémon, M., Grillo, M., Bruce, H., Kumar, S., Siwanowicz, I., Le, A., Lemire, A., Eisen, M.B., Extavour, C., Browne, W.E., Wolff, C., Averof, M., Patel, N.H., Sarkies, P., Pavlopoulos, A., Aboobaker, A., 2016. The genome of the crustacean Parhyale hawaiensis, a model for animal development, regeneration, immunity and lignocellulose digestion. eLife 5, e20062. https://doi.org/10.7554/eLife.20062

Kendrick, A.J., Hyndes, G. a., 2005. Variations in the dietary compositions of morphologically diverse syngnathid fishes. Environmental Biology of Fishes 72, 415-427. https://doi.org/10.1007/s10641-004-2597-y

Kitsos, M.-S., Tzomos, T., Anagnostopoulou, L., Koukouras, A., 2008. Diet composition of the seahorses, Hippocampus guttulatus Cuvier, 1829 and Hippocampus hippocampus (L., 1758) (Teleostei, Syngnathidae) in the Aegean Sea. Journal of Fish Biology 72, 1259-1267. https://doi.org/10.1111/j.1095-8649.2007.01789.x

Kolanowski, W., Stolyhwo, A., Grabowski, M., 2007. Fatty acid composition of selected fresh water gammarids (amphipoda, crustacea): A potentially innovative source of omega-3 LC PUFA. Journal of the American Oil Chemists' Society 84, 827-833. https://doi.org/10.1007/s11746-007-1116-7

Koldewey, H.J., Martin-Smith, K.M., 2010. A global review of seahorse aquaculture. Aquaculture 302, 131-152. https://doi.org/10.1016/j.aquaculture.2009.11.010

Lara, G., Furtado, P.S., Hostins, B., Poersch, L., Wasielesky Jr, W., 2016. Addition of sodium nitrite and biofilm in a Litopenaeus vannamei biofloc culture system. Latin american journal of aquatic research. https://doi.org/10.3856/vol44-issue4-fulltext-11

Legendre, P., Legendre, L., 1998. Numerical ecology, 2nd ed. Elsevier, Amsterdam.

Lin, Q., Lin, J., Zhang, D., Wang, Y., 2009. Weaning of juvenile seahorses Hippocampus erectus Perry, 1810 from live to frozen food. Aquaculture 291, 224-229. https://doi.org/10.1016/j.aquaculture.2009.03.031

Lourido, A., Moreira, J., Troncoso, J.S., 2008. Assemblages of peracarid crustaceans in subtidal sediments from the Ría de Aldán (Galicia, NW Spain). Helgoland Marine Research 62, 289-301. https://doi.org/10.1007/s10152-008-0116-9 
694 Magaña-Gallegos, E., González-Zúñiga, R., Arevalo, M., Cuzon, G., Chan-Vivas, E., López-

695

696

697

698

699

700

701

702

703

704

705

706

707

708

709

710

711

712

713

714

715

716

717

718

719

720

721

722

723

724

725

726

727

728 Aguiar, K., Noreña-Barroso, E., Pacheco, E., Valenzuela, M., Maldonado, C., Gaxiola, G., 2018. Biofloc and food contribution to grow-out and broodstock of Farfantepenaeus brasiliensis (Latreille, 1817) determined by stable isotopes and fatty acids. Aquaculture Research 49, 1782-1794. https://doi.org/10.1111/are.13632

Manning, C.G., Foster, S.J., Vincent, A.C.J., 2019. A review of the diets and feeding behaviours of a family of biologically diverse marine fishes (Family Syngnathidae). Reviews in Fish Biology and Fisheries 29, 197-221. https://doi.org/10.1007/s11160-019-09549-z

Martin, J.W., David, G.E., 2001. An updated classification of the recent Crustacea. Science Series (Los Angeles), 39. Natural History Museum of Los Angeles County: Los Angeles. VII, $123 \mathrm{pp}$.

Martinez-Cordova, L.R., Campaña Torres, A., Porchas-Cornejo, M.A., 2003. Dietary protein level and natural food management in the culture of blue (Litopenaeus stylirostris) and white shrimp (Litopenaeus vannamei) in microcosms. Aquaculture Nutrition 9, 155-160. https://doi.org/10.1046/j.1365-2095.2003.00235.x

McEvoy, L.A., Navarro, J.C., Bell, J.G., Sargent, J.R., 1995. Autoxidation of oil emulsions during the Artemia enrichment process. Aquaculture 134, 101-112. https://doi.org/10.1016/0044-8486(95)00048-7

Montgomery, D.C., Peck, E.A., 1992. Introduction to Linear Regression Analysis, 2nd ed. John Wiley \& Sons, New York.

Morgan, S. \& Bull, C., 2005. Potential techniques for tagging and marking seahorses. Project Seahorse Technical Report No.7, Version 1.0. Project Seahorse, Fisheries Centre, University of British Columbia. 27 pp.

Murugan, A., Dhanya, S., Sreepada, A., Rajagopal, S., Balasubramanian, T., Sreepada, R.A., Rajagopal, S., Balasubramanian, T., 2009. Breeding and mass-scale rearing of three spotted seahorse, Hippocampus trimaculatus Leach under captive conditions. Aquaculture 290, 8796. https://doi.org/10.1016/j.aquaculture.2009.01.033

National Research Council (NRC), 2011. Nutrient requirements of fish and shrimp. The National Academies Press, Washington, DC. https://doi.org/10.17226/13039

Navarro-Mayoral, S., Fernandez-Gonzalez V., Otero-Ferre, F., Tuya, F., 2020. Spatio-temporal variability of amphipod assemblages associated with rhodolith seabeds. Marine and Freshwater Research 72, 76-83. https://doi.org/10.1071/MF19360

Nieves-Soto, M., Lozano-Huerta, R., López-Peraza, D.J., Medina-Jasso, M.A., Hurtado-Oliva, M.A., Bermudes-Lizárraga, J.F., 2021. Effect of the enrichment time with the tuna orbital oil emulsion on the fatty acids profile of juveniles of Artemia franciscana. Aquaculture and

Peer] reviewing PDF | (2021:03:59365:2:0:CHECK 14 Sep 2021) 
729

730

731

732

733

734

735

736

737

738

739

740

741

742

743

744

745

746

747

748

749

750

751

752

753

754

755

756

757

758

759

760

761

762

763

Fisheries 6, 69-74. https://doi.org/10.1016/j.aaf.2020.03.008

Novelli, B., Otero-Ferrer, F., Diaz, M., Socorro, J.A., Caballero, M.J., Domínguez, L.M., Moyano, F.J., 2016. Digestive biochemistry as indicator of the nutritional status during early development of the long snouted seahorse (Hippocampus reidi). Aquaculture 464, 196-204. https://doi.org/10.1016/j.aquaculture.2016.06.037

Ofelio, C., Díaz, A.O., Radaelli, G., Planas, M., 2018. Histological development of the longsnouted seahorse Hippocampus guttulatus during ontogeny. Journal of Fish Biology 93, 7287. https://doi.org/10.1111/jfb.13668

Olivotto, I., Avella, M. a. A., Sampaolesi, G., Piccinetti, C., Navarro Ruiz, P., Carnevali, O., Ruiz, P.N., 2008. Breeding and rearing the longsnout seahorse Hippocampus reidi: rearing and feeding studies. Aquaculture 283, 92-96. https://doi.org/10.1016/j.aquaculture.2008.06.018

Olivotto, I., Chemello, G., Vargas, A., Randazzo, B., Piccinetti, C.C., Carnevali, O., 2017 a. Marine ornamental species culture: From the past to "Finding Dory." General and Comparative Endocrinology 245, 116-121. https://doi.org/10.1016/j.ygcen.2016.03.004

Olivotto, I., Planas, M., Simões, N., Holt, G.J., Avella, M.A., Calado, R., 2011. Advances in Breeding and Rearing Marine Ornamentals. Journal of the World Aquaculture Society 42, 135-166. https://doi.org/10.1111/j.1749-7345.2011.00453.x

Olivotto, I., Planas, M., Turchi, C., 2017b. Larval Diets and Nutrition, in: Calado, R., Olivotto, I., Planas, M., Holt, G.J. (Eds.), Marine Ornamental Species Aquaculture, Wiley Online Books. pp. 125-137. https://doi.org/10.1002/9781119169147.ch9

Palma, J., Stockdale, J., Correia, M., Andrade, J.P., 2008. Growth and survival of adult long snout seahorse (Hippocampus guttulatus) using frozen diets. Aquaculture 278, 55-59. https://doi.org/10.1016/j.aquaculture.2008.03.019

Payne, M.. F., Rippingale, R.. J., 2000. Rearing west australian seahorse, Hippocampus subelongatus, juveniles on copepod nauplii and enriched Artemia. Aquaculture 188, 353 361. https://doi.org/10.1016/S0044-8486(00)00349-5

Paz-Ríos, C.E., Simões, N., Ardisson, P.-L., 2013. Records and observations of amphipods (Amphipoda: Gammaridea and Corophiidea) from fouling assemblages in the Alacranes Reef, southern Gulf of Mexico. Marine Biodiversity Records 6, e90. https://doi.org/10.1017/S175526721300064X

Pinheiro, J., Bates, D., DebRoy, S., R Core Team, 2020. nlme: Linear and Nonlinear Mixed Effects Models. R package version 3.1-147., https://cran.r-project.org/package=nlme.

Planas, M., Olivotto, I., González, M.J., Laurà, R., Zarantoniello, M., 2020. A multidisciplinary experimental study on the effects of breeders diet on newborn seahorses (Hippocampus 
764

765

766

767

768

769

770

771

772

773

774

775

776

777

778

779

780

781

782

783

784

785

786

787

788

789

790

791

792

793

794

795

796

797

798

guttulatus). Frontiers in Marine Science. https://doi.org/10.3389/fmars.2020.00638

Planas, M., Silva, C., Quintas, P., Chamorro, A., Piñero, S., 2017. Ongrowing and enhancement of n-3 HUFA profile in adult Artemia: short- vs long-time enrichment. Journal of Applied Phycology 29, 1409-1420. https://doi.org/10.1007/s10811-016-1016-z

Poovachiranon, S., Boto, K., Duke, N., 1986. Food preference studies and ingestion rate measurements of the mangrove amphipod Parhyale hawaiensis (Dana). Journal of Experimental Marine Biology and Ecology 98, 129-140. https://doi.org/10.1016/00220981(86)90078-X

Promthale, P., Withyachumnarnkul, B., Bossier, P., Wongprasert, K., 2021. Nutritional value of the amphipod Bemlos quadrimanus sp. grown in shrimp biofloc ponds as influenced by different carbon sources. Aquaculture 533, 736128. https://doi.org/10.1016/j.aquaculture.2020.736128

Randazzo, B., Rolla, L., Ofelio, C., Planas, M., Gioacchini, G., Vargas, A., Giorgini, E., Olivotto, I., 2018. The influence of diet on the early development of two seahorse species (H. guttulatus and H. reidi): Traditional and innovative approaches. Aquaculture 490, 7590. https://doi.org/10.1016/j.aquaculture.2018.02.029

Saavedra, M., Masdeu, M., Hale, P., Sibbons, C.M., Holt, W. V, 2014. Dietary fatty acid enrichment increases egg size and quality of yellow seahorse Hippocampus kuda. Animal Reproduction Science 145, 54-61. https://doi.org/10.1016/j.anireprosci.2013.08.004

Sargent, J., McEvoy, L., Estevez, A., Bell, G., Bell, M., Henderson, J., Tocher, D., 1999. Lipid nutrition of marine fish during early development: current status and future directions. Aquaculture 179, 217-229. https://doi.org/10.1016/S0044-8486(99)00191-X

Schlechtriem, C., Arts, M.T., Johannsson, O.E., 2008. Effect of Long-term Fasting on the Use of Fatty Acids as Trophic Markers in the Opossum Shrimp Mysis relicta - A Laboratory Study. Journal of Great Lakes Research 34, 143-152. https://doi.org/10.3394/03801330(2008)34[143:EOLFOT]2.0.CO;2

Segade, Robaina, L., Novelli, B., Otero-Ferrer, F., Molina Domínguez, L., 2016. Effect of the diet on lipid composition and liver histology of short snout seahorse Hippocampus hippocampus. Aquaculture Nutrition 22, 1312-1319. https://doi.org/10.1111/anu.12341

Sgnaulin, T., de Mello, G.L., Thomas, M.C., Garcia, J.R.E., de Oca, G.A.R.M., Emerenciano, M.G.C., 2018. Biofloc technology (BFT): An alternative aquaculture system for piracanjuba Brycon orbignyanus? Aquaculture 485, 119-123. https://doi.org/10.1016/j.aquaculture.2017.11.043

Sorgeloos, P., Dhert, P., Candreva, P., 2001. Use of the brine shrimp, Artemia spp., in marine fish larviculture. Aquaculture 200, 147-159. https://doi.org/10.1016/S0044-8486(01)00698- 
799

800

801

802

803

804

805

806

807

808

809

810

811

812

813

814

815

816

817

818

819

820

821

822

823

824

825

826

827

828

829

830

831

832

833

6

Southgate, P.C., 2019. Hatchery and larval foods, in: Lucas, J.S., Southgate, P.C., Tucker, C.S. (Eds.), Aquaculture: Farming Aquatic Animals and Plants. Wiley-Blackwell, pp. 183-201.

Storero, L.P., González, R., 2008. Feeding habits of the seahorse Hippocampus patagonicus in San Antonio Bay (Patagonia, Argentina). Journal of the Marine Biological Association of the United Kingdom 88, 1503. https://doi.org/10.1017/S0025315408002506

Sun, D.A., Patel, N.H., 2019. The amphipod crustacean Parhyale hawaiensis: An emerging comparative model of arthropod development, evolution, and regeneration. Wiley Interdisciplinary Reviews: Developmental Biology 8, 1-20. https://doi.org/10.1002/wdev.355

Suontama, J., Karlsen, Ø., Moren, M., Hemre, G.-I., Melle, W., Langmyhr, E., Mundheim, H., Ringø, E., Olsen, R.E., 2007. Growth, feed conversion and chemical composition of Atlantic salmon (Salmo salar L.) and Atlantic halibut (Hippoglossus hippoglossus L.) fed diets supplemented with krill or amphipods. Aquaculture Nutrition 13, 241-255. https://doi.org/10.1111/j.1365-2095.2007.00466.x

Takeuchi, I., Matsumasa, M., \& Kikuchi, S., 2003. Gill ultrastructure and salinity tolerance of Caprella spp. (Crustacea: Amphipoda: Caprellidea) inhabiting the Sargassum community. Fisheries Science, 69(5), 966-973. https://doi.org/10.1046/j.1444-2906.2003.00714.x

Teixeira, R.L., Musick, J.A., Musik, J.A., 2001. Reproduction and food habits of the lined seahorse, Hippocampus erectus (Teleostei: Syngnathidae) of Chesapeake Bay, Virginia. Revista Brasileira de Biologia 61, 79-90.

Tocher, D.R., 2003. Metabolism and functions of lipids and fatty acids in Teleost. Reviews in fisheries science 11, 107-184.

Tocher, D.R., Agaba, M., Hastings, N., Teale, A.J., 2003. Biochemical and molecular studies of the polyunsaturated fatty acid desaturation pathway in fish, in: Browman, H.I., Skiftesvik, A.B. (Eds.), The Big Fish Bang: Proceedings of the 26th Annual Larval Fish Conference. Institute of Marine Research, Bergen, Norwary, pp. 211-227.

Vargas-Abúndez, A.J.A.J., Randazzo, B., Foddai, M., Sanchini, L., Truzzi, C., Giorgini, E., Gasco, L., Olivotto, I., 2019. Insect meal based diets for clownfish: Biometric, histological, spectroscopic, biochemical and molecular implications. Aquaculture 498, 1-11. https://doi.org/10.1016/j.aquaculture.2018.08.018

Vargas-Abúndez, J.A., López-Vázquez, H.I., Mascaró, M., Martínez-Moreno, G.L., Simões, N., 2021. Marine amphipods as a new live prey for ornamental aquaculture: exploring the potential of Parhyale hawaiensis and Elasmopus pectenicrus. PeerJ 9, e10840. https://doi.org/10.7717/peerj. 10840

Peerj reviewing PDF | (2021:03:59365:2:0:CHECK 14 Sep 2021) 
834 Vargas-Abúndez, J.A., Simões, N., Mascaró, M., 2018. Feeding the lined seahorse Hippocampus 835 erectus with frozen amphipods. Aquaculture 491, 82-85.

$836 \quad$ https://doi.org/10.1016/j.aquaculture.2018.02.043

837 Vázquez-Luis, M., Sanchez-Jerez, P., Bayle-Sempere, J.T., 2013. Does the invasion of Caulerpa 838 racemosa var. cylindracea affect the feeding habits of amphipods (Crustacea: Amphipoda)? 839 Journal of the Marine Biological Association of the United Kingdom 93, 87-94.

840 https://doi.org/10.1017/S0025315412000288

841

842

843

844

845

846

847

848

849

850

851

852

853

854

855

856

857

858

859

860

861

862
Wang, M., Jeffs, A.G., 2014. Nutritional composition of potential zooplankton prey of spiny lobster larvae: A review. Reviews in Aquaculture 6, 270-299. https://doi.org/10.1111/raq.12044

Wang, M., O’Rorke, R., Nodder, S.D., Jeffs, A.G., 2014. Nutritional composition of potential zooplankton prey of the spiny lobster phyllosoma (Jasus edwardsii). Marine and Freshwater Research 65, 337-349. https://doi.org/10.1071/MF13048

Wickham, H., 2016. ggplot2: Elegant Graphics for Data Analysis. Springer-Verlag New York.

Woods, C.M.C., 2009. Caprellid amphipods: An overlooked marine finfish aquaculture resource? Aquaculture 289, 199-211. https://doi.org/10.1016/j.aquaculture.2009.01.018

WoRMS Editorial Board, 2020. World Register of Marine Species [WWW Document]. URL www.marinespecies.org (accessed 2.26.20).

Xue, S., Mao, Y., Li, J., Zhu, L., Fang, J., Zhao, F., 2018. Life history responses to variations in temperature by the marine amphipod Eogammarus possjeticus (Gammaridae) and their implications for productivity in aquaculture. Hydrobiologia 814, 133-145. https://doi.org/10.1007/s10750-018-3524-0

Zhang, D., Lin, T., Liu, X., 2015. A Comparison of Growth, Survival, and Fatty Acid Composition of the Lined Seahorse, Hippocampus erectus, Juveniles Fed Enriched Artemia and a Calanoid Copepod, Schmackeria dubia. Journal of the World Aquaculture Society 46, 608-616. https://doi.org/10.1111/jwas.12233

Zuur, A., Leno, E., Smith, G., 2007. Analyzing Ecological Data. Springer-Verlag New York, USA. https://doi.org/10.1007/978-0-387-45972-1 
Figure 1

Principal coordinate analysis of fatty acid composition of four diets elaborated with amphipod $P$. hawaiensis of different source and enriched Artemia. 


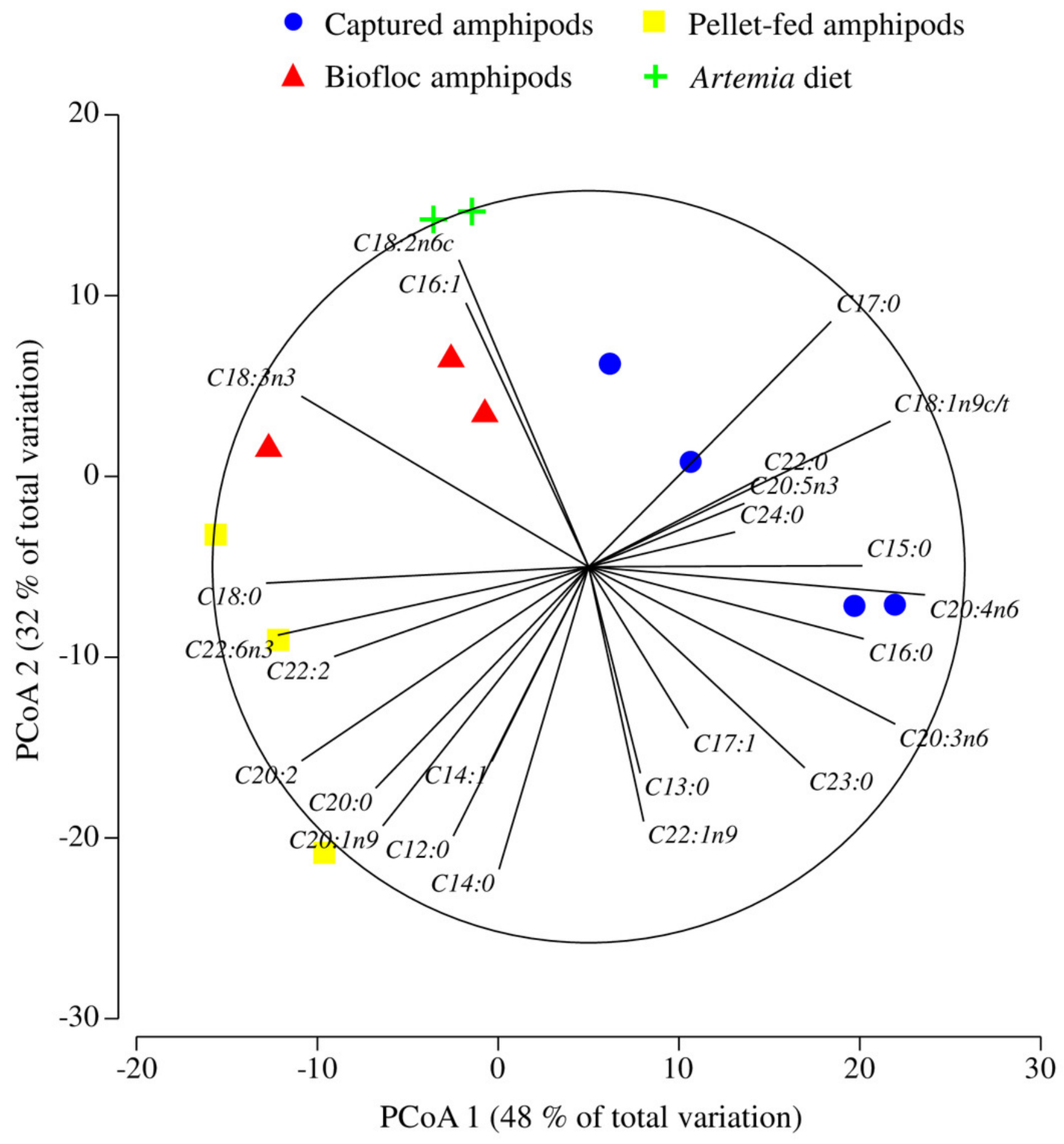


Figure 2

Non-metric Multidimensional Scaling (2D projection) of indices describing the fatty acid composition of amphipods $P$. hawaiensis of different source and enriched Artemia.

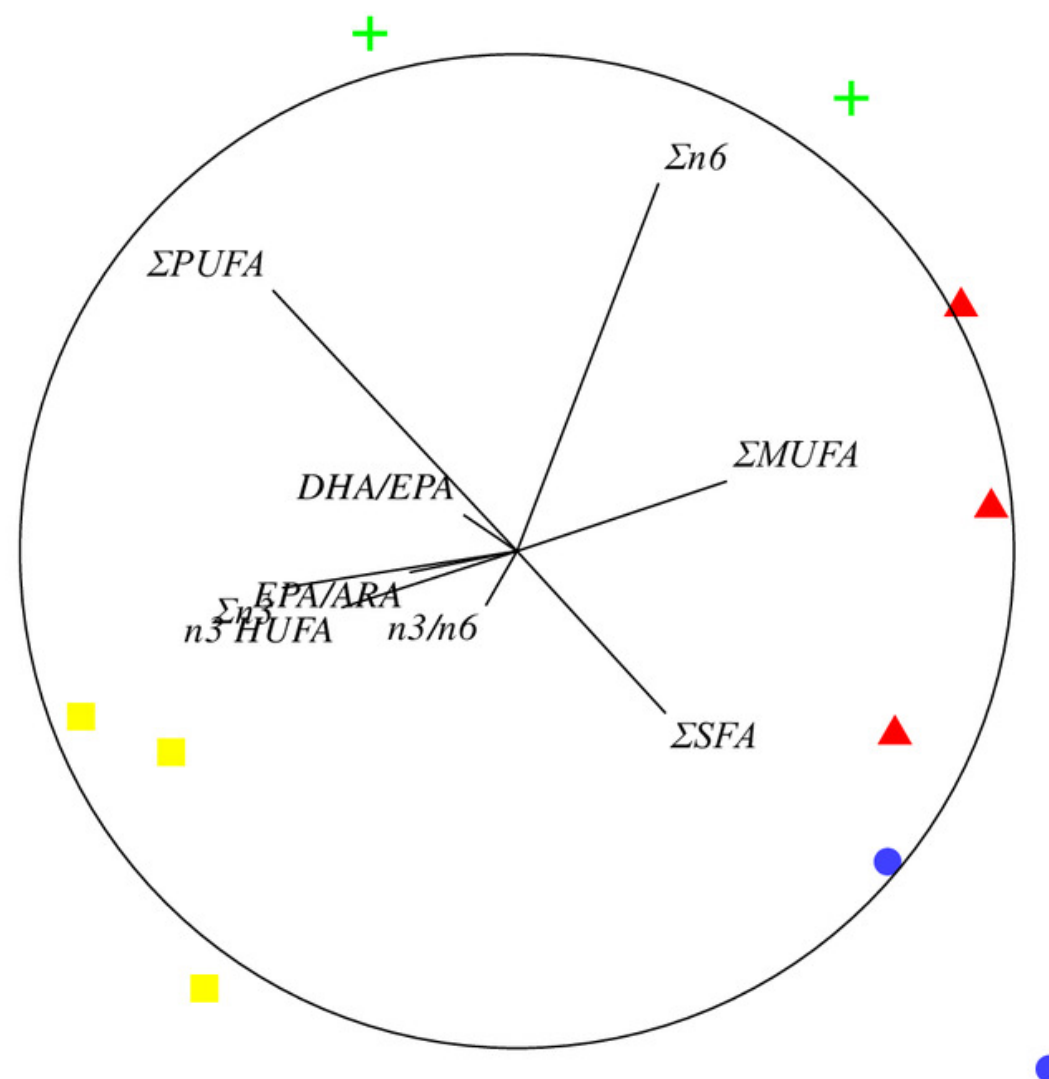

- Captured amphipods

- Biofloc amphipods

Pellet-fed amphipods

+ Artemia diet 
Figure 3

Wet weight $(\mathrm{g})$ of $H$. erectus fed captured amphipods (amphipod diet), enriched Artemia (Artemia diet), and a mixture (1:1) of the amphipod and the Artemia diets (mixed diet).

Error bars show \pm one standard deviation of the mean.

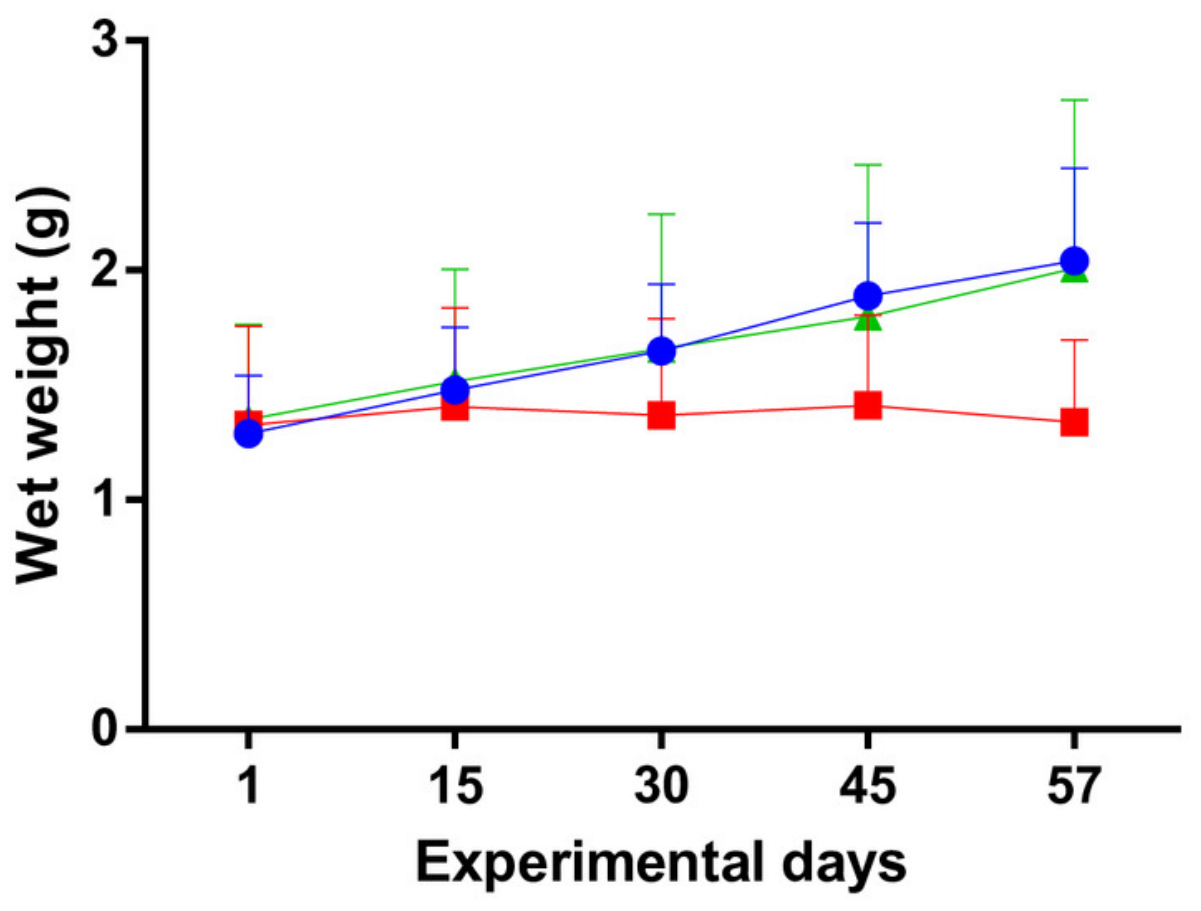

-- Amphipod Diet

$\rightarrow$ - Artemia Diet

$\_$Mixed Diet 
Figure 4

Principal coordinate analysis of fatty acid composition in tissue samples of $H$. erectus fed captured amphipods (amphipod diet), enriched Artemia (Artemia diet), and mixed (1:1) diet.

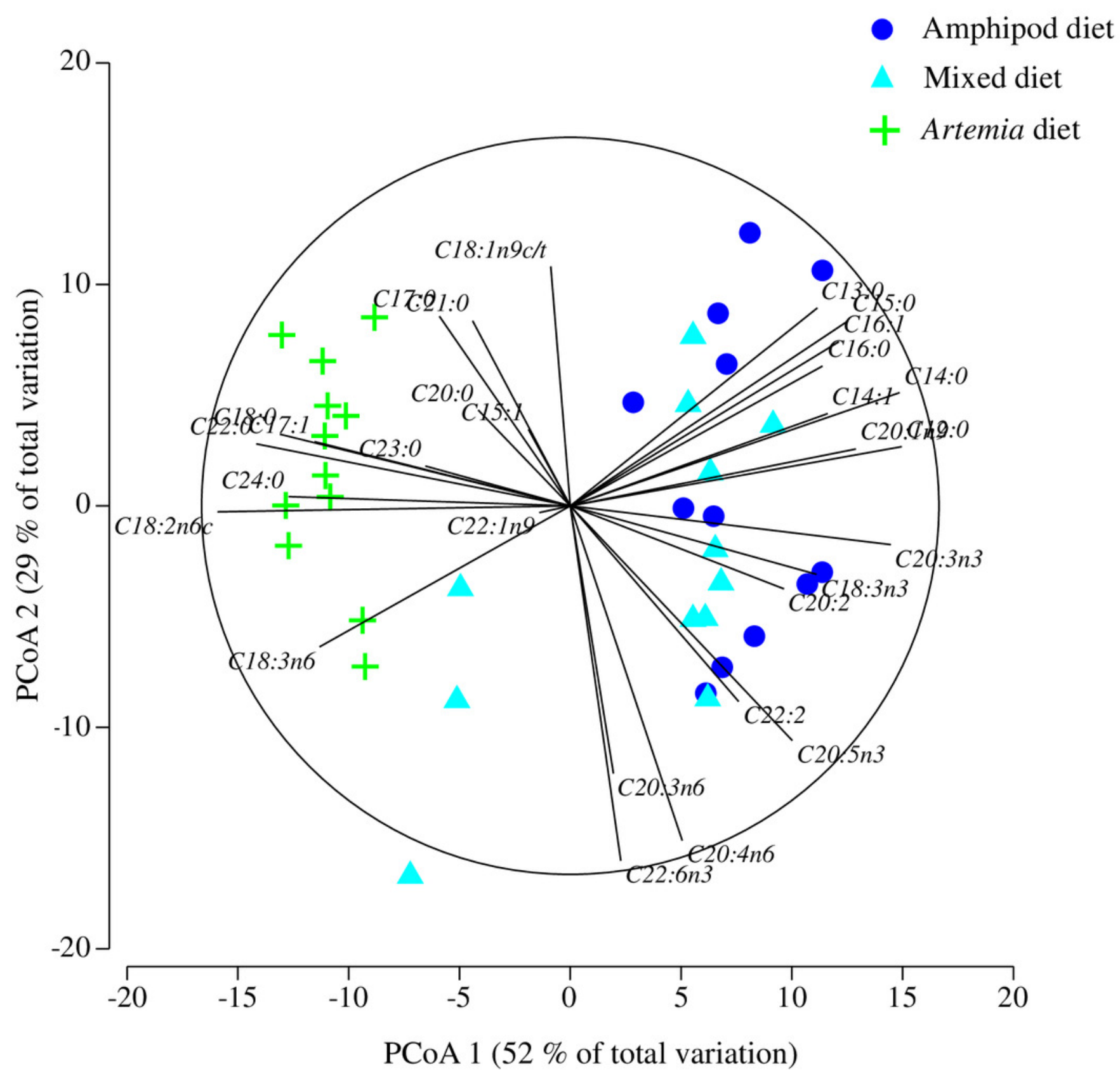


Figure 5

Non-metric Multidimensional Scaling (2D projection) of indices describing the fatty acid composition in tissue samples of seahorses $H$. erectus subjected to different dietary treatments.

Amphipod diet: captured amphipods; Artemia diet: enriched Artemia; mixed diet: a 1:1 mixture of the amphipod and Artemia diets.

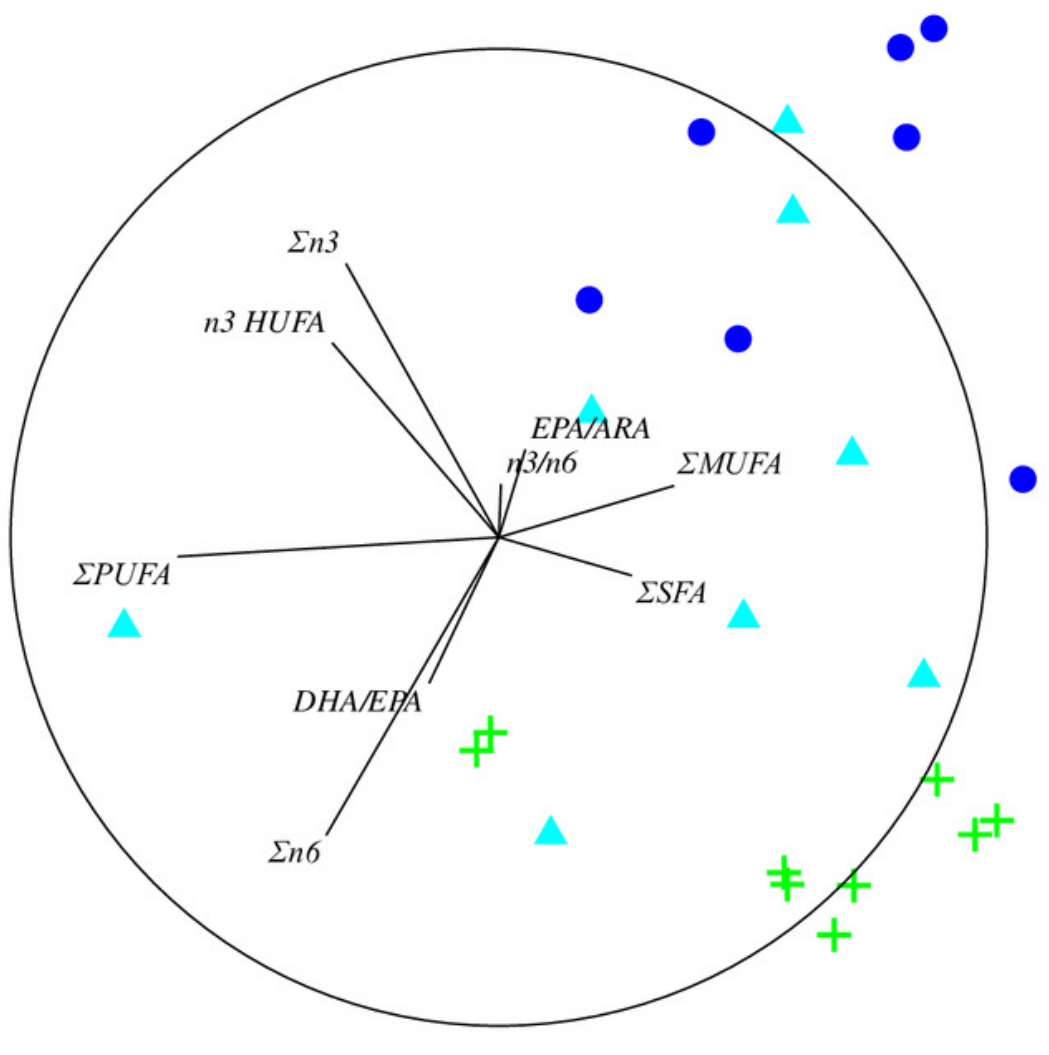

- Amphipod diet

Mixed diet

$+\quad$ Artemia diet

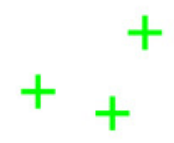




\section{Table $\mathbf{1}$ (on next page)}

Fatty acid composition (as percentage of total FAs) of $P$. hawaiensis of different source and enriched Artemia.

Data show \pm one standard deviation of the mean. 


\begin{tabular}{|c|c|c|c|c|}
\hline FAs & Captured amphipods & Biofloc amphipods & Pellet-fed amphipods & Artemia \\
\hline C12:0 & $0.4 \pm 0.21$ & $0.74 \pm 0.08$ & $0.81 \pm 0.12$ & $0.05 \pm 0.01$ \\
\hline C13:0 & $0.06 \pm 0$ & $0.06 \pm 0.01$ & $0.06 \pm 0.01$ & $0.04 \pm 0$ \\
\hline $\mathrm{C} 14: 0$ & $5.74 \pm 1.62$ & $7.36 \pm 0.68$ & $8.59 \pm 0.91$ & $1.71 \pm 0.18$ \\
\hline $\mathrm{C} 14: 1$ & $0.04 \pm 0$ & $0.05 \pm 0$ & $0.04 \pm 0$ & $0.01 \pm 0$ \\
\hline C15:0 & $0.97 \pm 0.06$ & $0.78 \pm 0.06$ & $0.59 \pm 0.19$ & $0.64 \pm 0.07$ \\
\hline $\mathrm{C} 16: 0$ & $22.49 \pm 7.96$ & $15.75 \pm 5.59$ & $14.97 \pm 0.69$ & $17.47 \pm 1.53$ \\
\hline C16:1 & $5.71 \pm 6.32$ & $6.44 \pm 1.67$ & $4.86 \pm 3.14$ & $9.22 \pm 1.08$ \\
\hline $\mathrm{C} 17: 0$ & $2.35 \pm 0.4$ & $1.3 \pm 0.08$ & $0.34 \pm 0.13$ & $2.43 \pm 0.19$ \\
\hline $\mathrm{C} 17: 1$ & $0.54 \pm 0.05$ & $0.23 \pm 0.14$ & $0.45 \pm 0.27$ & $0.14 \pm 0.02$ \\
\hline C18:0 & $8.23 \pm 2.64$ & $12.66 \pm 4.12$ & $13.89 \pm 2.71$ & $9.41 \pm 0.7$ \\
\hline $\mathrm{C} 18: \ln 9 \mathrm{c} / \mathrm{t}$ & $22.9 \pm 1.44$ & $18.23 \pm 5.21$ & $8.6 \pm 3.34$ & $15.71 \pm 2.81$ \\
\hline $\mathrm{C} 18: 2 \mathrm{n} 6 \mathrm{c}$ & $5.58 \pm 0.94$ & $14.8 \pm 2.11$ & $7.04 \pm 2.99$ & $20.78 \pm 1.06$ \\
\hline C18:3n6 & $1.19 \pm 0.77$ & $0.17 \pm 0.04$ & $5.51 \pm 1.76$ & $0 \pm 0$ \\
\hline C18:3n3 & $0.65 \pm 0.7$ & $2.12 \pm 0.12$ & $1.92 \pm 1.04$ & $2.23 \pm 0.09$ \\
\hline $\mathrm{C} 20: 0$ & $0.43 \pm 0.12$ & $0.44 \pm 0.06$ & $0.68 \pm 0.05$ & $0.27 \pm 0.03$ \\
\hline $\mathrm{C} 20: \ln 9$ & $2.34 \pm 0.18$ & $3.22 \pm 0.18$ & $4.12 \pm 1.06$ & $1.58 \pm 0.07$ \\
\hline $\mathrm{C} 20: 2$ & $0.8 \pm 0.14$ & $3.06 \pm 0.14$ & $4.19 \pm 0.17$ & $0.45 \pm 0.01$ \\
\hline C20:3n6 & $0.74 \pm 0.33$ & $0.19 \pm 0.03$ & $0.25 \pm 0.01$ & $0.05 \pm 0.03$ \\
\hline $\mathrm{C} 21: 0$ & $0.17 \pm 0.01$ & $0.12 \pm 0$ & $0.15 \pm 0.01$ & $0.02 \pm 0$ \\
\hline C20:3n 3 & $0.35 \pm 0.04$ & $0.65 \pm 0.03$ & $0.81 \pm 0.04$ & $0.03 \pm 0.01$ \\
\hline C20:4n6 & $7.68 \pm 2.62$ & $2.92 \pm 0.13$ & $2.98 \pm 0.12$ & $4.97 \pm 0.35$ \\
\hline $\mathrm{C} 20: 5 \mathrm{n} 3$ & $6.63 \pm 0.53$ & $4.26 \pm 0.2$ & $5.65 \pm 0.23$ & $6.94 \pm 0.95$ \\
\hline $\mathrm{C} 22: 0$ & $0.45 \pm 0.06$ & $0.22 \pm 0.04$ & $0.32 \pm 0.03$ & $0.49 \pm 0.12$ \\
\hline $\mathrm{C} 22: \ln 9$ & $0.34 \pm 0.03$ & $0.23 \pm 0.06$ & $0.35 \pm 0.05$ & $0.19 \pm 0.03$ \\
\hline $\mathrm{C} 22: 2$ & $0.09 \pm 0.08$ & $0.12 \pm 0.02$ & $0.18 \pm 0.01$ & $0.08 \pm 0.09$ \\
\hline $\mathrm{C} 23: 0$ & $0.21 \pm 0.07$ & $0.11 \pm 0.03$ & $0.13 \pm 0.02$ & $0.04 \pm 0.02$ \\
\hline $\mathrm{C} 24: 0$ & $0.25 \pm 0.16$ & $0.05 \pm 0.01$ & $0.09 \pm 0$ & $0.08 \pm 0.02$ \\
\hline $\mathrm{C} 22: 6 \mathrm{n} 3$ & $2.66 \pm 0.71$ & $3.72 \pm 0.19$ & $6.17 \pm 0.25$ & $4.72 \pm 1.33$ \\
\hline$\Sigma$ SFA & $41.74 \pm 6.19$ & $39.59 \pm 4.79$ & $40.61 \pm 1.53$ & $32.65 \pm 2.84$ \\
\hline$\Sigma$ MUFA & $31.87 \pm 5.97$ & $28.4 \pm 3.42$ & $18.41 \pm 6.18$ & $26.84 \pm 1.6$ \\
\hline$\Sigma$ PUFA & $26.38 \pm 2.35$ & $32.01 \pm 1.43$ & $34.7 \pm 3.71$ & $40.22 \pm 1.34$ \\
\hline n3 HUFA & $9.64 \pm 0.94$ & $8.63 \pm 0.42$ & $12.63 \pm 0.49$ & $11.66 \pm 2.28$ \\
\hline$\Sigma \mathrm{n} 3$ & $10.29 \pm 1.46$ & $10.75 \pm 0.53$ & $14.55 \pm 1.49$ & $13.89 \pm 2.19$ \\
\hline$\Sigma \mathrm{n} 6$ & $15.2 \pm 2.96$ & $18.07 \pm 1.98$ & $15.78 \pm 2.17$ & $25.8 \pm 0.74$ \\
\hline $\mathrm{n} 3 / \mathrm{n} 6$ & $0.71 \pm 0.21$ & $0.6 \pm 0.1$ & $0.93 \pm 0.06$ & $0.54 \pm 0.1$ \\
\hline DHA/EPA & $0.4 \pm 0.12$ & $0.87 \pm 0$ & $1.09 \pm 0.02$ & $0.67 \pm 0.1$ \\
\hline EPA/ARA & $0.95 \pm 0.34$ & $1.46 \pm 0.03$ & $1.9 \pm 0.01$ & $1.39 \pm 0.09$ \\
\hline
\end{tabular}

1 


\section{Table 2 (on next page)}

Results of a permutational MANOVA applied on the fatty acid composition of four diets elaborated with amphipod $P$. hawaiensis of different source and enriched Artemia.

df: degrees of freedom; SS multivariate sums of squares; multivariate mean squares; pseudo$F$, pseudo-t and $p: F$ and $t$ values obtained through permutations of the reduced model and the $p$ values associated; number of unique permutations used to obtain each pseudo- $F$ and pseudo-t value. 
1

\begin{tabular}{lcccccc}
\hline Source of variation & df & SS & MS & pseudo- $\boldsymbol{p}$ & $\boldsymbol{p}$ & $\begin{array}{c}\text { Unique } \\
\text { permutations }\end{array}$ \\
\hline Food source & 3 & 2617.2 & 872.4 & 7.5 & $<0.001$ & 9626 \\
Residual & 8 & 929.3 & 116.2 & & & \\
Total & 11 & 3546.5 & & & & \\
\hline
\end{tabular}

\begin{tabular}{lccc}
\hline Post-hoc comparisons & pseudo-t & $\boldsymbol{p}$ & $\begin{array}{c}\text { Unique } \\
\text { permutations }\end{array}$ \\
\hline Wild amphipods vs Biofloc amphipods & 2.5 & $<0.05$ & 35 \\
Wild amphipods vs Pellet amphipods & 3.2 & $<0.05$ & 35 \\
Biofloc amphipods vs Pellet amphipods & 3.5 & 0.10 & 10 \\
Artemia $v s$ Biofloc amphipods & 2.3 & 0.11 & 10 \\
Artemia $v$ S Pellet amphipods & 3.5 & 0.10 & 10 \\
Artemia $v s$ Wild amphipods & 2.5 & 0.07 & 15 \\
\hline
\end{tabular}

2

3 


\section{Table 3 (on next page)}

Results of a permutational MANOVA applied on several indices describing the fatty acid composition of amphipods $P$. hawaiensis of different source and enriched Artemia.

df: degrees of freedom; SS multivariate sums of squares; multivariate mean squares; pseudo$F$, pseudo-t and $p: F$ and $t$ values obtained through permutations of the reduced model and the $p$ values associated; number of unique permutations used to obtain each pseudo- $F$ and pseudo-t value. 


\begin{tabular}{lcccccc}
\hline Source of variation & df & SS & MS & pseudo- $\boldsymbol{p}$ & $\begin{array}{c}\text { Unique } \\
\text { permutations }\end{array}$ \\
\hline Food source & 3 & 6777.1 & 2259 & 8.4 & $<0.001$ & 9586 \\
Residual & 8 & 2148.7 & 268.6 & & & \\
Total & 11 & 8925.8 & & & & \\
\hline Post-hoc comparisons & & & pseudo-t & $\boldsymbol{p}$ & $\begin{array}{c}\text { Unique } \\
\text { permutations }\end{array}$ \\
\hline Wild amphipods $v$ s Biofloc amphipods & & 1.8 & $<0.05$ & 35 \\
Wild amphipods $v$ Pellet amphipods & & 3.6 & $<0.05$ & 35 \\
Biofloc amphipods vs Pellet amphipods & & 4.2 & 0.09 & 10 \\
Artemia $v$ Biofloc amphipods & & 2.6 & 0.09 & 10 \\
Artemia $v$ Pellet amphipods & & 3.4 & 0.09 & 10 \\
Artemia $v s$ Wild amphipods & & & 2.5 & 0.07 & 15 \\
\hline
\end{tabular}




\section{Table 4 (on next page)}

Results of $t$-tests comparing the intercepts and slopes of three lineal regressions on the changes in wet weight $(\mathrm{g})$ of $H$. erectus as a function of time (days) when fed the experimental diets.

Amphipod: amphipod diet; Artemia: Artemia diet; Mixed: mixed diet, ns: non-significant; *** $\mathrm{p}$ $<0.001$ (see text for details on the GLMM adjusted to the data). 
1

2

3

\begin{tabular}{lcccc}
\hline & \multicolumn{2}{c}{ Intercept } & \multicolumn{2}{c}{ Slope } \\
\hline \multirow{3}{*}{ Mixed } & Amphipod & Mixed & Amphipod & Mixed \\
\cline { 2 - 5 } Artemia & $0.47 \mathrm{~ns}$ & - & $1.08 \mathrm{~ns}$ & - \\
& $0.16 \mathrm{~ns}$ & $0.62 \mathrm{~ns}$ & $8.76 * * *$ & $6.49 * * *$ \\
\hline
\end{tabular}

4

Artemia

$8.76 * * *$ 


\section{Table 5 (on next page)}

Variance estimates $\left(\sigma^{2}\right)$ associated to mean biomass of $H$. erectus fed with three diets (captured amphipods, enriched Artemia and a mixed (1:1) diet) on days $0,15,30,45$ and 57 of the experiment.

Estimates were obtained with a generalized least-square procedure through restricted maximum likelihood and included a variance exponential structure. 


\begin{tabular}{llll}
\hline & \multicolumn{3}{c}{ Diet } \\
\cline { 2 - 4 } Days & Amphipod & Mixed & Artemia \\
\hline 0 & 0.121 & 0.121 & 0.121 \\
15 & 0.144 & 0.157 & 0.107 \\
30 & 0.170 & 0.202 & 0.093 \\
45 & 0.201 & 0.261 & 0.082 \\
57 & 0.231 & 0.320 & 0.074 \\
\hline
\end{tabular}

1 


\section{Table 6(on next page)}

Fatty acid composition ( $\%$ of total FAs) of $H$. erectus fed captured amphipods (amphipod diet), enriched Artemia (Artemia diet), and a mixed diet (1:1; mixed diet) throughout a 57-day experiment

Data show \pm one standard deviation of the mean. 


\begin{tabular}{|c|c|c|c|}
\hline FAs & Amphipod diet & Artemia diet & Mixed diet \\
\hline C12:0 & $0.25 \pm 0.06$ & $0.09 \pm 0.15$ & $0.2 \pm 0.1$ \\
\hline C13:0 & $0.08 \pm 0.02$ & $0.05 \pm 0.01$ & $0.1 \pm 0$ \\
\hline C14:0 & $4.49 \pm 0.9$ & $1.6 \pm 0.22$ & $3.6 \pm 1.1$ \\
\hline $\mathrm{C} 14: 1$ & $0.03 \pm 0.01$ & $0.09 \pm 0.29$ & $0.01 \pm 0.01$ \\
\hline C15:0 & $0.88 \pm 0.15$ & $0.59 \pm 0.06$ & $0.78 \pm 0.14$ \\
\hline C15:1 & $0.03 \pm 0.02$ & $0.03 \pm 0.03$ & $0.02 \pm 0.02$ \\
\hline C16:0 & $24.05 \pm 3.12$ & $19.52 \pm 2.24$ & $24.84 \pm 4.16$ \\
\hline C16:1 & $8.31 \pm 2.2$ & $4.72 \pm 0.43$ & $6.2 \pm 2.44$ \\
\hline C17:0 & $1.57 \pm 0.56$ & $1.78 \pm 0.27$ & $1.5 \pm 0.47$ \\
\hline $\mathrm{C} 17: 1$ & $0.53 \pm 0.24$ & $1.09 \pm 0.25$ & $0.61 \pm 0.38$ \\
\hline C18:0 & $12.42 \pm 3.93$ & $17.72 \pm 1.81$ & $15.23 \pm 2.58$ \\
\hline $\mathrm{C} 18: \ln 9 \mathrm{c} / \mathrm{t}$ & $20.37 \pm 2.96$ & $20.28 \pm 2.95$ & $16.24 \pm 4.48$ \\
\hline $\mathrm{C} 18: 2 \mathrm{n} 6 \mathrm{c}$ & $3.43 \pm 0.24$ & $15 \pm 1.09$ & $6.21 \pm 2.36$ \\
\hline C18:3n6 & $0.34 \pm 0.08$ & $0.58 \pm 0.15$ & $0.43 \pm 0.14$ \\
\hline $\mathrm{C} 18: 3 \mathrm{n} 3$ & $1.01 \pm 0.22$ & $0.61 \pm 0.15$ & $0.77 \pm 0.17$ \\
\hline C20:0 & $0.48 \pm 0.09$ & $0.56 \pm 0.09$ & $0.41 \pm 0.16$ \\
\hline $\mathrm{C} 20: \ln 9$ & $1.43 \pm 0.24$ & $0.8 \pm 0.08$ & $1.22 \pm 0.28$ \\
\hline C20:2 & $0.51 \pm 0.06$ & $0.35 \pm 0.1$ & $0.44 \pm 0.1$ \\
\hline C20:3n6 & $0.35 \pm 0.06$ & $0.32 \pm 0.05$ & $0.34 \pm 0.07$ \\
\hline $\mathrm{C} 21: 0$ & $0.14 \pm 0.02$ & $0.17 \pm 0.09$ & $0.09 \pm 0.05$ \\
\hline $\mathrm{C} 20: 4 \mathrm{n} 6$ & $7.48 \pm 2.24$ & $5.53 \pm 1.39$ & $8.39 \pm 2.33$ \\
\hline $\mathrm{C} 20: 3 \mathrm{n} 3$ & $0.3 \pm 0.05$ & $0.07 \pm 0.04$ & $0.22 \pm 0.06$ \\
\hline $\mathrm{C} 20: 5 \mathrm{n} 3$ & $4.61 \pm 1.68$ & $2.39 \pm 0.85$ & $4.08 \pm 1.28$ \\
\hline $\mathrm{C} 22: 0$ & $0.45 \pm 0.06$ & $0.82 \pm 0.11$ & $0.49 \pm 0.16$ \\
\hline $\mathrm{C} 22: \ln 9$ & $0.31 \pm 0.05$ & $0.3 \pm 0.09$ & $0.35 \pm 0.26$ \\
\hline $\mathrm{C} 22: 2$ & $0.18 \pm 0.1$ & $0.08 \pm 0.06$ & $0.15 \pm 0.11$ \\
\hline $\mathrm{C} 23: 0$ & $0.09 \pm 0.03$ & $0.14 \pm 0.05$ & $0.11 \pm 0.06$ \\
\hline $\mathrm{C} 24: 0$ & $0.28 \pm 0.05$ & $0.45 \pm 0.08$ & $0.3 \pm 0.12$ \\
\hline $\mathrm{C} 22: 6 \mathrm{n} 3$ & $5.6 \pm 2.46$ & $4.29 \pm 1.92$ & $6.65 \pm 2.8$ \\
\hline$\Sigma$ SFA & $45.18 \pm 3.11$ & $43.5 \pm 4.22$ & $47.66 \pm 5.62$ \\
\hline$\Sigma$ MUFA & $31.02 \pm 4.91$ & $27.31 \pm 2.95$ & $24.67 \pm 5.02$ \\
\hline$\Sigma$ PUFA & $23.81 \pm 6.41$ & $29.21 \pm 5.33$ & $27.67 \pm 7.43$ \\
\hline n3 HUFA & $10.51 \pm 3.9$ & $6.75 \pm 2.75$ & $10.96 \pm 3.61$ \\
\hline$\Sigma \mathrm{n} 3$ & $11.51 \pm 4$ & $7.35 \pm 2.87$ & $11.72 \pm 3.64$ \\
\hline$\Sigma \mathrm{n} 6$ & $11.61 \pm 2.43$ & $21.42 \pm 2.47$ & $15.36 \pm 4.19$ \\
\hline $\mathrm{n} 3 / \mathrm{n} 6$ & $0.97 \pm 0.17$ & $0.33 \pm 0.1$ & $0.76 \pm 0.15$ \\
\hline DHA/EPA & $1.22 \pm 0.32$ & $1.75 \pm 0.21$ & $1.66 \pm 0.59$ \\
\hline EPA/ARA & $0.62 \pm 0.15$ & $0.42 \pm 0.08$ & $0.5 \pm 0.16$ \\
\hline
\end{tabular}




\section{Table 7 (on next page)}

Results of a permutational MANOVA applied on the fatty acid composition in samples of $H$. erectus fed captured amphipods (amphipod diet), enriched Artemia (Artemia diet), and mixed (1:1) diet.

df: degrees of freedom; SS multivariate sums of squares; multivariate mean squares; pseudo$F$, pseudo-t and $p: F$ and $t$ values obtained through permutations of the reduced model and the $p$ values associated; number of unique permutations used to obtain each pseudo- $F$ and pseudo-t value. 


\begin{tabular}{lcccccc}
\hline Source of variation & df & SS & MS & pseudo- & $\boldsymbol{p}$ & $\begin{array}{c}\text { Unique } \\
\text { permutations }\end{array}$ \\
\hline Diet & 2 & 2607.2 & 1303.6 & 15.0 & $<0.001$ & 9920 \\
Individual (Diet) & 15 & 1301.9 & 86.8 & 1.2 & 0.28 & 9907 \\
Residual & 18 & 1310.4 & 72.8 & & & \\
Total & 35 & 5219.5 & & & & \\
\hline Post-hoc comparisons & & & pseudo-t & $\boldsymbol{p}$ & $\begin{array}{c}\text { Unique } \\
\text { permutations }\end{array}$ \\
\hline Amphipod $v$ M Mixed diet & & & 1.9 & $<0.05$ & 462 \\
Amphipod $v$ Artemia diet & & & 6.3 & $<0.01$ & 461 \\
Artemia $v$ s Mixed diet & & & 3.7 & $<0.01$ & 462 \\
\hline
\end{tabular}

1 


\section{Table 8(on next page)}

Results of a permutational MANOVA applied on indices describing the fatty acid composition of $H$. erectus fed captured amphipods (amphipod diet), enriched Artemia (Artemia diet), and mixed (1:1) diet.

df: degrees of freedom; SS multivariate sums of squares; multivariate mean squares; pseudo$F$, pseudo-t and $p: F$ and $t$ values obtained through permutations of the reduced model and the $p$ values associated; number of unique permutations used to obtain each pseudo- $F$ and pseudo-t value. 


\begin{tabular}{lcccccc}
\hline Source of variation & df & SS & MS & pseudo- $\boldsymbol{p}$ & $\boldsymbol{p}$ & $\begin{array}{c}\text { Unique } \\
\text { permutations }\end{array}$ \\
\hline Diet & 2 & 5799.7 & 2899.8 & 7.6 & $<0.001$ & 9913 \\
Individual (Diet) & 15 & 5701.6 & 380.1 & 1.3 & 0.24 & 9914 \\
Residual & 18 & 5419.7 & 301.1 & & & \\
Total & 35 & 16921 & & & & \\
\hline Post-hoc comparisons & & & pseudo-t & $\boldsymbol{p}$ & $\begin{array}{c}\text { Unique } \\
\text { permutations }\end{array}$ \\
\hline Amphipod $v$ Mixed diet & & & 1.8 & 0.06 & 462 \\
Amphipod $v$ Artemia diet & & & 4.4 & $<0.01$ & 462 \\
Artemia $v$ s Mixed diet & & & 2.3 & $<0.01$ & 462 \\
\hline
\end{tabular}

1 